Journal for ImmunoTherapy of Cancer

\section{CD161 expression and regulation defines rapidly responding effector CD4+ T cells associated with improved survival in HPV16-associated tumors}

To cite: Duurland CL, Santegoets SJ, Abdulrahman Z, et al. CD161 expression and regulation defines rapidly responding effector CD4+ $T$ cells associated with improved survival in HPV16associated tumors. Journal for ImmunoTherapy of Cancer 2022;10:e03995. doi:10.1136/ jitc-2021-003995

- Additional supplemental material is published online only. To view, please visit the journal online (http://dx.doi.org/10. 1136/jitc-2021-003995).

Accepted 21 November 2021

Check for updates

(C) Author(s) (or their employer(s)) 2022. Re-use permitted under CC BY. Published by BMJ.

For numbered affiliations see end of article.

Correspondence to

Professor Sjoerd H van der Burg; shvdburg@lumc.nl

\section{ABSTRACT}

Background Expression of killer cell lectin-like receptor $\mathrm{B} 1$ (KLRB1), the gene encoding the cell surface molecule CD161, is associated with favorable prognosis in many cancers. CD161 is expressed by several lymphocyte populations, but its role and regulation on tumor-specific $\mathrm{CD} 4+\mathrm{T}$ cells is unknown.

Methods We examined the clinical impact of CD4+CD161+ T cells in human papillomavirus (HPV)16+ oropharyngeal squamous cell carcinoma (OPSCC), analyzed their contribution in a cohort of therapeutically vaccinated patients and used HPV16-specific CD4+CD161+ tumor-infiltrating lymphocytes and T cell clones for in-depth mechanistic studies.

Results Central and effector memory CD4+ T cells express CD161, but only CD4+CD161+ effector memory T cells (Tem) are associated with improved survival in OPSCC. Therapeutic vaccination activates and expands type 1 cytokine-producing CD4+CD161+ effector T cells. The expression of CD161 is dynamic and follows a pattern opposite of the checkpoint molecules PD1 and CD39. CD161 did not function as an immune checkpoint molecule as demonstrated using multiple experimental approaches using antibodies to block CD161 and gene editing to knockout CD161 expression. Single-cell transcriptomics revealed KLRB1 expression in many $T$ cell clusters suggesting differences in their activation. Indeed, CD4+CD161+ effector cells specifically expressed the transcriptional transactivator SOX4, known to enhance T cell receptor (TCR) signaling via CD3 $\varepsilon$. Consistent with this observation, CD4+CD161+ cells respond more vigorously to limiting amounts of cognate antigen in presence of interleukin (IL)-12 and IL-18 compared to their CD161- counterparts. The expression of CD161/KLRB1 and SOX4 was downregulated upon TCR stimulation and this effect was boosted by transforming growth factor (TGF) $\beta 1$.

Conclusion High levels of CD4+CD161+ Tem are associated with improved survival and our data show that CD161 is dynamically regulated by cell intrinsic and extrinsic factors. CD161 expressing CD4+ T cells rapidly respond to suboptimal antigen stimulation suggesting that
CD161, similar to SOX4, is involved in the amplification of TCR signals in CD4+ T cells.

\section{BACKGROUND}

Infection with human papillomavirus type 16 (HPV16) can cause tumors in the oropharynx and cervix. ${ }^{1}$ Presence of an intratumoral type $1 \mathrm{~T}$ cell response against the viral oncoproteins E6 and E7 (immune response (IR)+) is strongly associated with improved survival in oropharyngeal squamous cell carcinoma (OPSCC). Mass cytometry analysis of the tumor microenvironment (TME) revealed that HPV16+IR+ OPSCC and cervical cancer were highly infiltrated by CD4+CD161+ effector cells. $^{23}$

CD161 is a C-type lectin receptor expressed on natural killer (NK) cells and $\mathrm{T}$ cells in peripheral blood, umbilical cord blood, and thymus. ${ }^{5}$ (Tumor-specific) CD4+CD161+ and CD8+CD161+ cells produce more proinflammatory cytokines compared to CD161cells. $^{2367}$ Transcriptional profling of CD4+, CD8+ and $\gamma \delta+\mathrm{T}$ cells expressing CD161 identified a shared transcriptional profile and innate-like function among these cell lineages. ${ }^{8}$ Lectin-like transcript 1 (LLT1), the ligand for CD161, is expressed by activated B cells and dendritic cells (DC), but also malignant cells. ${ }^{9-14}$ CD161 functions as a coinhibitory receptor on NK cells, but on $\mathrm{T}$ cells the function is less clear as studies reported a costimulatory, coinhibitory, or no function for CD161. 8101213 15-17

In this study, we examined the role and regulation of CD161 expression on tumorspecific CD4+ cells. Our data show that CD4+CD161+ effector memory T cells (Tem) are associated with improved survival and 
can be activated upon therapeutic vaccination. CD161 does not function as an immune checkpoint molecule on CD4+ cells. Instead, CD161 expression on CD4+ cells is dynamically regulated and coexpressed with the transcriptional transactivator SOX4, and CD4+CD161+ cells respond more vigorously to cognate antigen stimulation under suboptimal conditions.

\section{MATERIALS AND METHODS Patient samples}

All patients received standard-of-care treatment and HPV typing was performed. ${ }^{18}$ Formalin-fixed paraffinembedded (FFPE) biopsies of 40 histologically confirmed OPSCC patients were included (HPV16+IR+ n=25, HPV16+IR-n=15). Peripheral blood mononuclear cells (PBMC) were isolated from venous blood of healthy donors and patients using ficoll density gradient centrifugation, cryopreserved and stored until use.

\section{Multispectral immunofluorescence}

A multispectral immunofluorescence panel containing CD3, CD8, PD1, CD45RO, CD161 and DAPI (online supplemental table 1) was designed and optimized, ${ }^{19}$ see online supplemental material.

\section{Analysis of HPV16-specific T cells after vaccination}

PBMC and skin biopsies were collected during studies examining the effect of vaccination in HPV16+ vulvar or vaginal intraepithelial neoplasia. ${ }^{2021} \mathrm{PBMC}$ were obtained before (prevaccination) and 2 weeks postvaccination. Skin biopsies from the vaccination site were obtained 2 weeks postvaccination. Infiltrating $\mathrm{T}$ cells were isolated ${ }^{2}$ and cultured in 10\% $\mathrm{T}$ cell Growth Factor (TCGF, ZeptoMetrix), recombinant human interleukin-7 (rhIL7), rhIL-15 (5 ng/mL) (PeproTech) and Gentamicin CF $(20 \mu \mathrm{g} / \mathrm{mL}$, Centrafarm). Cells were cryopreserved upon sufficient expansion.

Prevaccination and postvaccination PBMC were prestimulated for 11 days with a pool of 22-mer E6 and E7 (E6E7) peptides (final concentration of each peptide: $2.5 \mu \mathrm{g} / \mathrm{mL}$ ) to expand antigen-specific T cells. 10\% TCGF and $5 \mathrm{ng} / \mathrm{mL}$ rhIL-15 were added after 1 day of culture. Expanded PBMC and cultured $\mathrm{T}$ cells were stimulated with monocytes loaded overnight with a pool of 22-mer E6 and E7 peptides (final concentration of each peptide: $5 \mu \mathrm{g} / \mathrm{mL}$ ). Monocytes were isolated from autologous PBMC by adherence and cultured with granulocyte-macrophage colony-stimulating factor (GMCSF) $(800 \mathrm{U} / \mathrm{mL}$, Thermo Fisher Scientific (TFS) ) for 3 days. Brefeldin A (10 $\mu \mathrm{g} / \mathrm{mL}$, Sigma) was added after 1 hour and cells were incubated overnight before analysis of cytokine production by flow cytometry.

\section{Flow cytometry and cell sorting}

Cells were stained with LIVE-DEAD fixable Yellow or near-IR dead cell stain kit (TFS), incubated with phosphate-buffered saline (PBS) containing $0.5 \%$ bovine serum albumin (Sigma) (FACS buffer) and $10 \%$ FCS for 10 min at $4^{\circ} \mathrm{C}$, washed and stained with fluorochrome-conjugated antibodies (online supplemental table 2) for $20 \mathrm{~min}$ at $4^{\circ} \mathrm{C}$. Intracellular cytokine production in response to vaccination and rhIL-12 + rhIL-18 was analyzed. ${ }^{23}$ Alternatively, cells were fixated and stained intracellularly using BD Cytofix/Cytoperm kit according to manufacturer's instructions. For LLT1 staining, cells were blocked with $10 \%$ goat serum (Dako/Agilent) and $100 \mu \mathrm{g} /$ $\mathrm{mL}$ IgG from human serum (Sigma) in FACS buffer for 30 min, washed, incubated with $10 \mu \mathrm{g} / \mathrm{mL}$ purified mouse-antihuman IgG1 (clone MOPC-21, Biolegend) or LLT1 (clone 4F68, V.M. Braud) for $30 \mathrm{~min}$, washed and incubated with goat-anti-mouse PE (Biolegend) for $30 \mathrm{~min}$. Flow cytometry data were acquired using a BD LSR Fortessa and analyzed using FlowJo software V.10.7.1 (BD).

For cell sorting, cells were used directly after culture, or thawed and enriched for CD4+ cells using the human CD4+ T cell isolation kit (Miltenyi Biotech). Cells were stained with LIVE/DEAD near-IR dead cell stain kit and fluorochrome-conjugated antibodies (online supplemental table 2) as described above, but cells were washed in FACS buffer supplemented with 2 mM EDTA (Sigma). Cells were sorted using BD FACS Aria I or III.

\section{Killer cell lectin-like receptor B1 (KLRB1) gene editing of primary human $\mathrm{T}$ cells}

Expanded CD4+CD161+ cells from OPSCC tumor-infiltrating lymphocytes (TIL) or HPV16-specific CD4+CD161+ T cell clones (see online supplemental material) were thawed and rested overnight in 10\% Iscove's Modified Dulbecco's Medium (IMDM) containing rhIL-2 $(1000 \mathrm{U} / \mathrm{mL}$, Aldesleukin, Novartis) and rhIL-7 (5 ng/mL) (OPSCC TIL), or rhIL2, rhIL-7 and rhIL-15 (5 ng/mL) (HPV16-specific T cell clones) followed by electroporation with ribonucleoproteins (RNPs) containing guide RNA (gRNA) targeting KLRB1 or control. ${ }^{22}$ CrisprRNA targeting human $K L R B 1^{10}$ or control (catalog\# 1072544) (Integrated DNA Technologies (IDT)) were suspended to $100 \mu \mathrm{M}$ in nuclease-free duplex buffer. gRNA were generated by incubating $10 \mu \mathrm{l}$ of $100 \mu \mathrm{M}$ crRNA targeting KLRB1 region\#1, KLRB1 region \#2, or control with $10 \mu \mathrm{L}$ tracrRNA. To prepare the RNP complex, $3 \mu \mathrm{L}$ annealed gRNA targeting KLRB1 region\#1, KLRB1 region \#2, or control was mixed with $2 \mu \mathrm{L}$ Cas9 per sample and incubated for $10 \mathrm{~min}$ at room temperature. Before nucleofection, cells were washed in PBS and resuspended in 20 $\mu 1$ P2 Nucleofection buffer (Lonza), $1 \mu \mathrm{L}$ of $100 \mu \mathrm{M}$ Alt-R cas9 electroporation enhancer (IDT) per nucleofection, and $5 \mu \mathrm{L}$ control RNP or $2.5 \mu \mathrm{L}$ KLRB1 region\#1 RNP and 2.5 $\mu L$ KLRB1 region\#2 RNP. Mixes were transferred to a 16-well nucleocuvette strip and samples were electroporated using a 4D-nucleofector machine (Lonza) with program EH100. Samples were cultured for 7 days in 10\% IMDM containing rhIL-2, rhIL-7 and rhIL-15 as above.

\section{Functional analysis of CD161}

Cells were stimulated with plate-bound anti-CD3 (R\&D, clone UCHL1, various concentrations), anti-IgG1 (clone MOPC-21) or anti-CD161 (clone HP-3G10) (Biolegend) (HPV16-specific CD4+ T cell clones: $5 \mu \mathrm{g} / \mathrm{mL}$, OPSCG 
TIL: $10 \mu \mathrm{g} / \mathrm{mL}$ ). Alternatively, cells were preincubated with biotinylated anti-IgG1 (clone MOPC-21) or antiCD161 (clone HP-3G10) (Biolegend, $5 \mu \mathrm{g} / \mathrm{mL}$ ) for 30 min, washed, and crosslinked with anti-biotin antibody (Stemcell Technologies, $5 \mu \mathrm{g} / \mathrm{mL}$ ) during stimulation with plate-bound anti-CD3 $(1 \mu \mathrm{g} / \mathrm{mL})$ and soluble antiCD28 (2 $\mu \mathrm{g} / \mathrm{mL}, \mathrm{BD}$, clone CD28.2) 2 days before coculture, autologous B lymphoblastoid cell lines (B-LCL) were cultured $\left(0.25 \times 10^{6}\right.$ cells $\left./ \mathrm{mL}\right)$ and after 1 day loaded overnight with indicated amounts of 22-mer E6 and E7 peptides (pool or specific peptide). T cells were preincubated with plate-bound anti-IgG1 or anti-CD161 (10 $\mu \mathrm{g} / \mathrm{mL}$ ) for 1 hour before coculture with irradiated (7500 RAD) peptide-loaded B-LCL at indicated ratio's. Cells were cultured for 4 hours in presence of Brefeldin A $(10 \mu \mathrm{g} / \mathrm{mL})$ or 24 hours with Brefeldin A added after 1 hour of culture and analyzed by intracellular cytokine staining, or 3 days and analyzed for interferon $\gamma$ (IFN $\gamma$ ) and GM-CSF secretion using ELISA (Mabtech).

\section{T cell stimulation and culture with cycloheximide, transforming growth factor (TGF) B1, Activin A, bone morphogenetic protein (BMP)2, BMP6, rhlL-12, and rhIL-18}

CD4+, or sorted CD4+CD8-(CD45RO+)CD161+ or CD161cells from healthy donors, or HPV16-specific CD4+ T cell clones were cultured directly or first labeled with CellTrace Violet (CTV, $2 \mu \mathrm{M}$, TFS). (CTV-labeled) cells were stimulated with anti-CD3CD28 beads (TFS) at indicated bead:cell ratio's or irradiated (7500 RAD) peptide-loaded B-LCL (B-LCL:T cell is 1:5) for 5 days. Additionally, cells were stimulated with transforming growth factor $\beta 1$ (TGF 31$)(0,1,5 \mathrm{ng} / \mathrm{mL}$, PeproTech) for 5 days or 3 weeks in $10 \%$ IMDM and rhIL-7 (healthy donor) or rhIL-15 (clones) $(5 \mathrm{ng} / \mathrm{mL})$. TGF $\beta 1$ and rhIL-7 were added every 3-4 days to 3-week cultures and cells were restimulated with anti-CD3CD28 every week. For restimulation, cells were harvested and anti-CD3CD28 beads were removed using a magnet before restimulation. TGF $\beta 1$, rhIL-7 and rhIL-15 were added to 5-day cultures every 2 days. Cells were preincubated with $1 \mu \mathrm{M}$ SB505124 (Tocris) or dimethyl sulfoxide (DMSO) for 2 hours followed by 2 hours preincubation with TGF $\beta 1$ before adding antiCD3CD28 beads. Alternatively, TGF $\beta 1$ was preincubated with $10 \mu \mathrm{g} / \mathrm{mL}$ pan-neutralizing TGF $\beta 1$ (clone 1D11) or control (clone 13C4) antibody for 2 hours in 10\% IMDM before preincubation with cells for 2 hours. SB505124, DMSO, pan-neutralizing TGF $\beta$ antibody or control, and TGF $\beta 1$ were added to cultures every 2 days.

Healthy donor-derived CD4+ cells were cultured with 20 $\mu \mathrm{g} / \mathrm{mL}$ cycloheximide (CHX) or DMSO, Activin A $\pm 1 \mu \mathrm{M}$ SB505124, bone morphogenetic protein 2 (BMP2) or BMP6 $(0,10,50,100,200 \mathrm{ng} / \mathrm{mL})$ as described for TGF $\beta 1$.

HPV16-specific CD4+ T cell clones were stimulated with peptide-loaded B-LCL in presence or absence of $50 \mathrm{ng} / \mathrm{mL}$ rhIL-12 (Milteny Biotech) and rhIL-18 (R\&D systems). Cells were cultured for 24 hours with $5 \mu \mathrm{g} / \mathrm{mL}$ Brefeldin A during the last 4 hours of culture.

\section{Imaging mass cytometry (hyperion)}

Imaging mass cytometry was performed using an optimized 33-marker panel. $^{23}$ The generated highdimensional output was analyzed by an in-house developed imaging processing pipeline combining multiple previously validated publicly available software programs (Abdulrahman et al submitted), see online supplemental material.

\section{RNA isolation, $\mathrm{qPCR}$ and $\mathrm{T}$ cell Receptor analysis}

RNA was extracted using Arcturus Picopure RNA isolation kit (TFS) according to manufacturer's instructions using the protocol for isolation of RNA from cell pellets. cDNA was synthesized using high-capacity RNAto-cDNA kit (TFS) and amplified using iQ SYBR Green Mastermix (Bio-Rad) and primers (Sigma) against target genes (online supplemental table 3). Relative expression of KLRB1 upon T cell receptor (TCR) stimulation was normalized to average expression of $B A C T$ and $B 2 M$, relative expression of KLRB1 upon TGF $\beta 1$ exposure to $S D H A$, and relative expression of BACH2, EOMES, SATB1, $L E F 1, T C F 7$ and SOX4 to average expression of $B 2 M$ and $S D H A$ using the $2^{-\Delta \mathrm{Cq}}$ method. Expression relative to 0 $\mathrm{ng} / \mathrm{mL}$ TGF $\beta 1$ was calculated using the $2^{-\Delta \Delta \mathrm{Cq}}$ method. TCR sequencing of the T cell Receptor Beta chain from sorted CD4+CD161+ or CD161- T cell clones and analysis was performed by iRepertoire.

\section{Single-cell RNA sequencing and data analysis}

Single-cell OPSCC tumor digests were analyzed by singlecell RNA sequencing (Abdulrahman et al submitted), see online supplemental material. External Smart-seq2 datasets of $\mathrm{T}$ cells from non-small cell lung cancer (NSCLC), ${ }^{24}$ colorectal cancer $(\mathrm{CRC})^{25}$ and hepatocellular carcinoma (HCC) ${ }^{26}$ were obtained from EGA under accession numbers EGAS00001002430, EGAD00001003910 and EGAS00001002072, respectively. Raw FASTQ files were processed using the nf-core Smart-seq2 pipeline (https://nfco.re/smartseq2). Read counts were loaded into scanpy and filtered for cells with $>2000$ detected genes, and $<16 \%$ mitochondrial reads. The cell-type labels from the original publications were used. A Nextflow pipeline ${ }^{27}$ to reproduce the analyses is publicly available from GitHub (https://github. com/icbi-lab/duurland2021_paper).

\section{Statistical analysis}

Statistical analysis was performed using GraphPad Prism V.9.0.1. For survival analysis, patients were grouped into high and low numbers of cell population based on the median level in all patients combined and statistical significance was analyzed by log-rank testing. Non-parametric (Wilcoxon matched-pairs signed rank test or MannWhitney with Holm-Š́dák multiple comparison test), one-way analysis of variance (ANOVA) Kruskal-Wallis with Dunn's multiple comparison test, and RM Two-Way ANOVA or mixed model in case of missing values with Geisser-Greenhouse correction with Tukey's or Šídák's multiple comparisons test were performed as appropriate. 

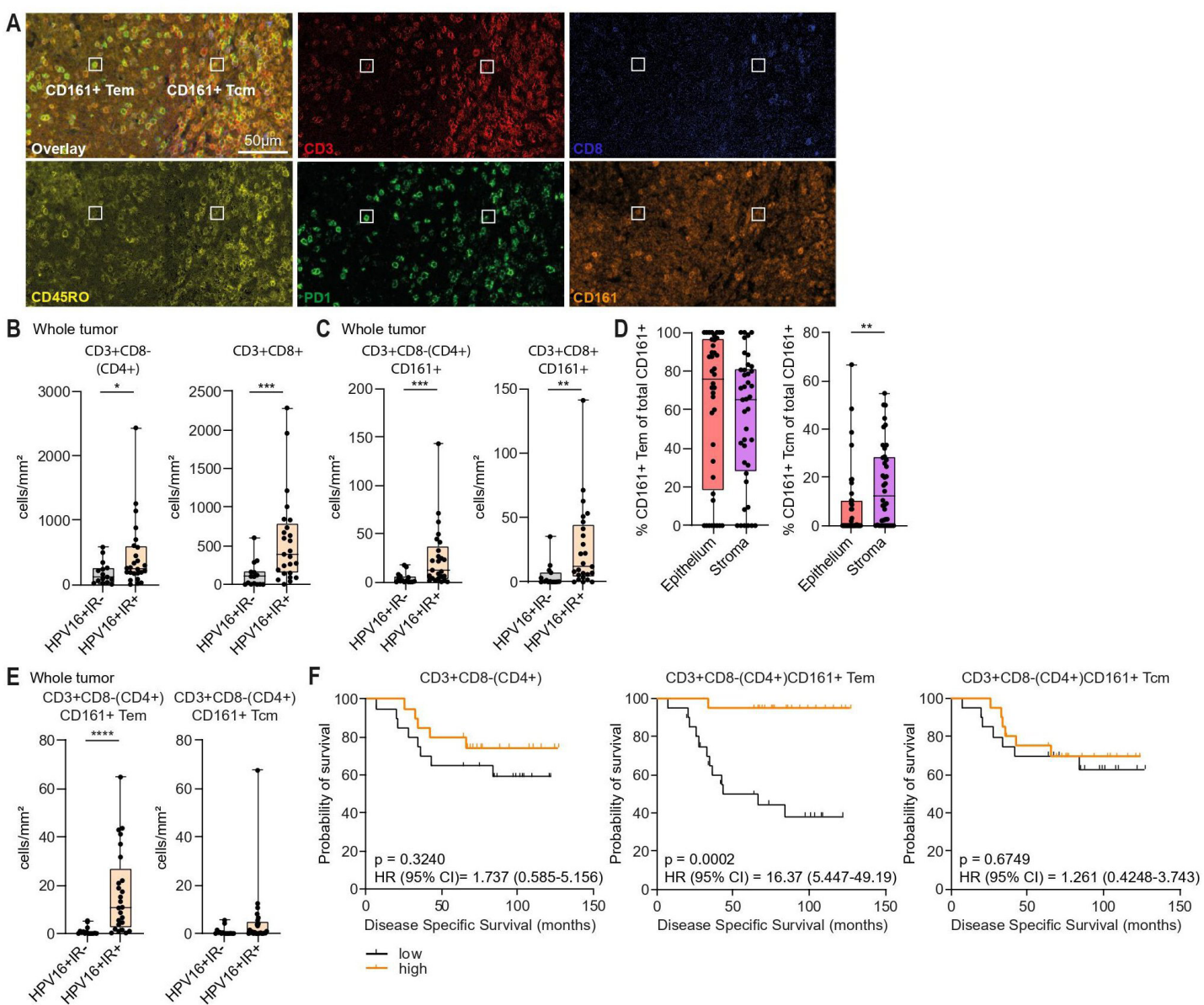

Figure 1 Tumor-infiltrating CD4+CD161+ Tem are associated with improved survival. Formalin-fixed paraffin-embedded (FFPE) sections of OPSCC tumor tissue from HPV16+IR- $(n=15)$ and HPV16+IR+ $(n=25)$ patients were analyzed by immunofluorescence with antibodies against CD3, CD8, CD161, CD45RO, PD1. (A) Overlay and single stains of DAPI, CD3, CD8, CD45RO, PD1, CD161 immunofluorescence staining in a representative HPV16+IR+ sample. White squares indicate CD4+CD161+ Tem and Tcm cells. (B) Summary graphs showing number of CD3+CD8-(CD4+) and CD3+CD8+ T cells $/ \mathrm{mm}^{2}$ in tumor tissue of HPV16+IR- and HPV16+IR+ patients. (C) Summary graphs showing number of CD3+CD8-(CD4+)CD161+ and $\mathrm{CD} 3+\mathrm{CD} 8+\mathrm{CD} 161+\mathrm{cells} / \mathrm{mm}^{2}$ in tumor tissue of HPV16+IR- and HPV16+IR+ patients. (D) Summary graph showing percentage CD161+ Tem and Tcm of total CD161+ T cells in epithelium and stroma. (E) Summary graphs showing cells $/ \mathrm{mm}^{2}$ for CD3+CD8-(CD4+)CD161+ Tem and CD3+CD8-(CD4+)CD161+ Tcm in HPV16+IR- and HPV16+IR+ patients. (F) Kaplan-Meier survival curves showing survival of patients divided into below (low) or above (high) median numbers of CD3+CD8-(CD4+) cells, CD3+CD8-(CD4+)CD161+ Tem and CD3+CD8-(CD4+)CD161+ Tcm. ${ }^{*} \mathrm{p}<0.05,{ }^{* *} \mathrm{p}<0.01,{ }^{* * *} \mathrm{p}<0.001,{ }^{* * * *} \mathrm{p}<0.0001$. HPV16, human papillomavirus 16; IR+/-, immune response positive/negative; Tcm, central memory T cells; Tem, effector memory $\mathrm{T}$ cells.

Where used, lines or bar graphs represent mean or median, and error bars represent standard deviation (SD) or standard error of the mean (SEM) as indicated in figure legends. $\mathrm{P}$ values below 0.05 were considered significant and are shown in graphs as ${ }^{*} \mathrm{p}<0.05$, $* \mathrm{p} p<0.01$, $* * * \mathrm{p}<0.001, * * * * \mathrm{p}<0.0001$.

\section{RESULTS}

\section{Tumor-infiltrating CD4+CD161+ Tem are associated with improved survival}

To determine the relevance of CD161 expressing T cells, the TME of 40 OPSCC patients was analyzed using multispectral immunofluorescence (figure 1A). The numbers of total CD3+CD8- (CD4+) (99\% of CD3+CD8- T cells are $\mathrm{CD} 4+{ }^{19}$ ), CD3+CD8+ cells (figure 1B), CD4+CD161+ and
CD8+CD161+ cells (figure 1C) were significantly higher in HPV16+ immune response positive (IR+) compared with HPV16+ IR negative (IR-) patients. Our previously published mass cytometry analysis demonstrated an enrichment of CD4+CD161+ Tem, but not CD4+CD161+ central memory T cells $(\mathrm{Tcm})$, in the TME of HPV16+IR+ patients. ${ }^{23}$ Reanalysis of this data ${ }^{2}$ showed that distinct expression patterns of CD45RO and PD1 between Tem and Tcm allowed for discrimination between CD161+ Tem and Tcm (online supplemental figure 1A-B). The percentage CD161+ Tem was similar between epithelium and stroma, whereas the percentage CD161+ Tcm was higher in stroma compared to epithelium (figure 1D). The TME of HPV16+IR+ patients showed a significant enrichment of CD4+CD161+ Tem, but not Tcm, compared to HPV16+IR-patients (figure 1E). 
For CD8+ cells, numbers of tumor-infiltrating CD161+ Tem and Tcm were higher in HPV16+IR+ compared to HPV16+IR- (online supplemental figure 1C). Numbers of tumor-infiltrating $\mathrm{CD} 4+$ cells were not associated with disease-specific survival (DSS), but subgrouping patients based on CD4+CD161+ Tem numbers resulted in a clear separation of survival curves with increased DSS for the group of patients with high CD4+CD161+ Tem levels. This was not the case when patients were grouped by CD4+CD161+ Tcm numbers (figure 1F). Similar analysis for $\mathrm{CD} 3+\mathrm{CD} 8+$ cell populations showed no additional improvement of DSS when CD8+CD161+ Tem or Tcm were grouped compared to total CD8+ cells (online supplemental figure 1D). Thus, specifically CD4+CD161+ Tem are associated with better clinical outcome in OPSCC.

\section{Type 1 cytokine-producing CD4+CD161+ T cells are expanded upon vaccination}

The prognostic impact of $\mathrm{CD} 4+\mathrm{CD} 161+$ Tem provides rationale for the investigation of strategies to boost this population.
To explore this, biological samples from patients treated with a clinically effective therapeutic HPV16 vaccine ${ }^{20} 21$ were used. Prevaccination and postvaccination PBMC (pre- and post-PBMC), prestimulated in vitro with a pool of HPV16 E6E7 peptides to expand HPV16-specific T cells, and T cells cultured from skin biopsies taken from the vaccination site were examined for presence of HPV16-specific responses by CD4+CD161+ cells. Stimulation with E6E7 peptides resulted in detection of IFN $\gamma+$, tumor necrosis factor (TNF) $\alpha+$ and activated $(\mathrm{CD} 154+/ \mathrm{CD} 137+$ single and double positive (SP and DP)) $\mathrm{CD} 4+$ cells (online supplemental figure 2A-C), which were increased in peripheral blood after vaccination and present at the vaccination site. In vitro expansion of prePMBC and post-PMBC induced a shift in memory phenotype of $\mathrm{CD} 4+$ cells and cells adopted a Tem phenotype, especially postvaccination (figure 2A), but total percentages of CD4+CD161+ cells were not altered (online supplemental figure 2D). Both CD4+CD161+ and CD4+CD161- cell populations contained HPV16-specific T cells producing IFN $\gamma$
A

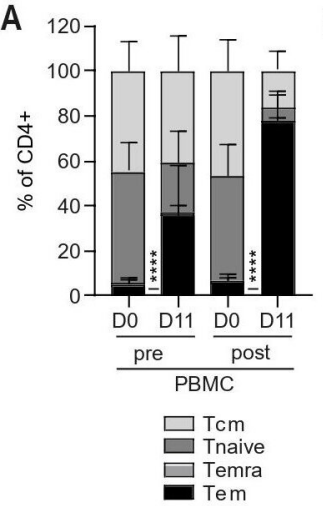

B
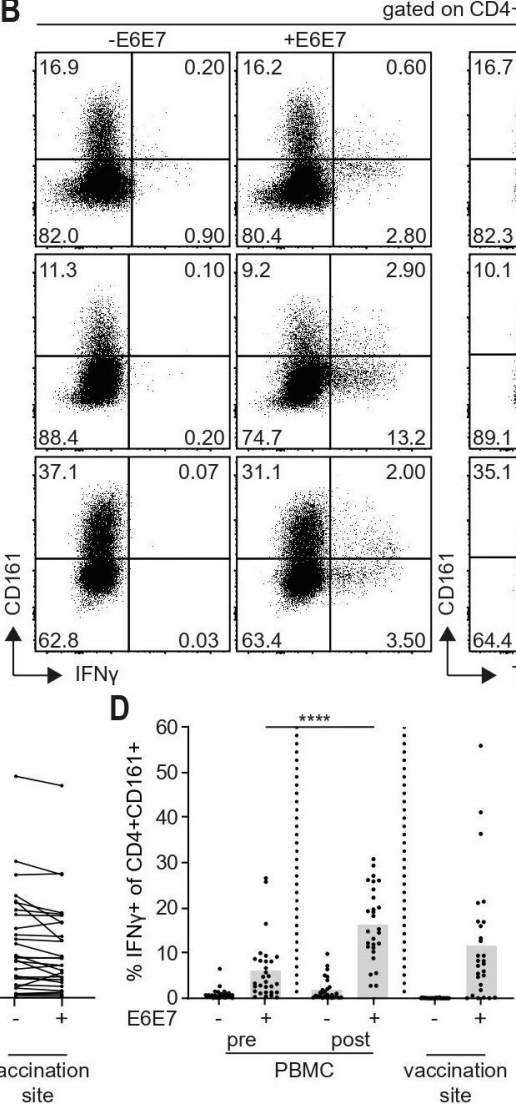

ated on CD4+
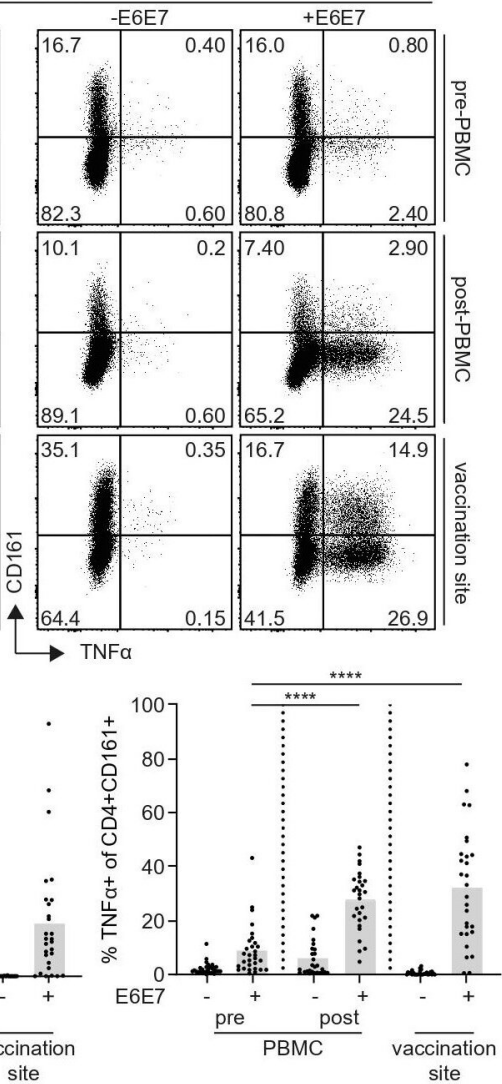

Figure 2 Type 1 cytokine-producing CD4+CD161+ T cells are expanded upon vaccination. (A) PBMC prevaccination $(n=28)$ and postvaccination( $(n=30)$ (pre-PBMC and post-PBMC) were prestimulated with a pool of E6E7 peptides $(2.5 \mu \mathrm{g} / \mathrm{mL}$ of each peptide) for 11 days to generate bulk cultures. Summary graph depicting percentages Tcm, Tnaive, Temra and Tem of CD4+ cells among pre-PBMC and post-PBMC on day 0 (D0) and after 11 days (D11) prestimulation with E6E7 peptide pool. Graph shows mean \pm SD. (B, C) Prestimulated pre-PBMC $(n=28)$ and post-PBMC $(n=30)$, and cultured T cells from the vaccination site $(n=28)$ were stimulated overnight with autologous monocytes loaded with a pool of E6E7 peptides $(5 \mu \mathrm{g} / \mathrm{mL}$ of each peptide) and analyzed by intracellular cytokine staining. (B) Representative dot plots showing IFN $\gamma$ and TNF $\alpha$ against CD161 gated on CD4+ cells. (C) Summary graph showing percentage CD161+ cells of CD4+ cells upon stimulation with or without E6E7 peptide pool. (D) Summary graph showing percentage IFN $\gamma+$ and TNF $\alpha+$ of CD4+CD161+ cells upon stimulation with or without E6E7 peptide pool. Bar graphs show mean. ${ }^{* * \star *} \mathrm{p}<0.0001$. IFN $\gamma$, interferon $\gamma$, PBMC, peripheral blood mononuclear cells; Tcm, central memory T cells; Tem; effector memory T cells; TNF $\alpha$, tumor necrosis factor $\alpha$. 
and $\mathrm{TNF} \alpha$ upon antigen-specific stimulation (figure $2 \mathrm{~B}-\mathrm{D}$; online supplemental figure 2E). Furthermore, their frequencies were increased after vaccination (figure 2D) indicating that cytokine-producing $\mathrm{CD} 4+\mathrm{CD} 161+$ cells are boosted by therapeutic vaccination.

\section{CD161 does not affect cytokine production by CD4+ T cells}

The effect of the interaction between CD161 and its ligand LLT1 on T cell function is unclear and studies used distinct experimental approaches to examine this. ${ }^{8} 10121315-17$ The function of CD161 was analyzed using in vitro expanded CD4+CD161+ TIL and CD4+CD161+ T cell clones derived from HPV16+IR+ OPSCC patients according to the approaches depicted in figure 3A. First, cells were stimulated with plate-bound anti-CD3 and anti-IgG1 or anti-CD161. In agreement with previous findings, ${ }^{13} 1528$ TCR stimulation was required for cells to produce IFN $\gamma$ and TNF $\alpha$, but specific CD161 engagement on CD4+CD161+ TIL and clones had no consistent effect on cytokine production compared to isotype control (figure 3B-D). Second, cells were stimulated with biotinylated anti-CD161 or anti-IgG1 followed by crosslinking with an anti-biotin antibody during CD3-mediated TCR stimulation and CD28 costimulation, but again no consistent effect was observed (figure 3E). Incubation with anti-CD161 was efficient as indicated by reduced detection of CD161 (online supplemental figure 3A-D). In the third approach, cells were stimulated with cognate antigen presented by LLT1 expressing target cells to interrogate the function of the CD161-LLT1 interaction in a more physiological antigenspecific setting. LLT1 is expressed on Epstein Barr Virus (EBV)-transformed B-LCL, ${ }^{12}{ }^{13}$ including those generated from OPSCC and cervical cancer patients (figure 3F). Stimulation with cognate antigen resulted in production of IFN $\gamma$ and TNF $\alpha$, but no effect of anti-CD161 was observed after 24 or 72 hours of stimulation (figure 3G-H). CD161 expression could not be detected after stimulation with anti-CD161 indicating that blockade was efficient (online supplemental figure $3 \mathrm{E}$ ). We observed that activated $\mathrm{T}$ cells also express LLT1, which was gradually lost over time (figure 3I). This may complicate CD161 blocking experiments, because LLT1 and CD161 can directly interact with each other on T cells before the antibody does. Recently, a coinhibitory effect of CD161 on antigen-specific CD8+ T cells was demonstrated using $\mathrm{T}$ cells in which expression of $K L R B 1$ was edited for inactivation ${ }^{10}$ (figure 3A). Crispr-Cas9-mediated editing of KLRB1 in CD4+CD161+ OPSCC TIL and HPV16-specific $\mathrm{CD} 4+\mathrm{CD} 161+\mathrm{T}$ cell clones was highly effective (figure 3J, online supplemental figure $3 \mathrm{~F}$ ), but did not consistently affect the response of $\mathrm{T}$ cells upon stimulation with peptideloaded LLT1 expressing B-LCL (figure 3K-L). Thus, in all four approaches, no consistent effect on cytokine production by $\mathrm{CD} 4+$ cells was observed, ruling out a role for CD161 as coinhibitory receptor on $\mathrm{CD} 4+$ cells.

CD161 expression is dynamic upon TCR triggering and in time Analysis of a series of HPV16-specific CD4+ T cell clones with distinct cytokine producing phenotypes (online supplemental figure $4 \mathrm{~A}$ ) revealed a significant reduction in percentage of cells expressing CD161 after 7 days of stimulation (figure 4A). Detailed monitoring of CD161 expression during culture revealed four distinct patterns based on percentage CD161+ cells. Group I showed high percentages of CD161+ cells at start of culture followed by a reduction on day 7 after stimulation, but in time percentages returned to the levels observed at start of culture until the next antigenic stimulation. Group II showed similar kinetics as group $\mathrm{I}$, but percentages of $\mathrm{CD} 161+$ cells were intermediate. Percentages of CD161+ cells in group III were low at start of culture and remained low. Group IV followed a distinct pattern as percentages of CD161+ cells were initially reduced after stimulation, but then increased in time (figure 4B). To explore the dynamics of CD161 protein expression, CD161+ and CD161- cells were sorted from HPV16-specific CD4+ T cell clones belonging to group I-III (online supplemental figure 4B). Interestingly, CD161- sorted cells from clones that were at least 25\%-30\% CD161+ before sorting re-expressed CD161 again in time whereas CD161+ sorted cells remained highly CD161+. The percentage of CD161+ cells sorted from clones which were $<20 \% \mathrm{CD} 161+$ was reduced with time and sorted CD161- cells remained CD161- (figure 4C). Human T cell Receptor Beta Variable (TRBV) gene repertoire analysis of CD4+CD161+ and CD161- cells after cell sorting showed that both cell populations had the same TRBV chain and thus originate from a single $\mathrm{T}$ cell clone (figure $4 \mathrm{D}$ ). These data indicate that CD161 expression is dynamic in time and influenced by TCR-mediated signaling.

\section{Downregulation of CD161 protein expression depends on TCR- signaling strength}

To further decipher the effect of TCR stimulation on CD161 expression, CD4+CD161+ and CD161- cells were sorted from healthy donor-derived PBMC (online supplemental figure 5A), stimulated with anti-CD3CD28 beads at different ratio's and analyzed after 5 days of culture based on the kinetics of expression on $\mathrm{T}$ cell clones. We focused on $\mathrm{CD} 4+\mathrm{CD} 45 \mathrm{RO}+$ cells as circulating $\mathrm{CD} 4+\mathrm{CD} 161+$ cells are mainly $\mathrm{CD} 45 \mathrm{RO}+$ memory cells while $\mathrm{CD} 4+\mathrm{CD} 161-$ cells are a mixture of $\mathrm{CD} 45 \mathrm{RO}+$ and CD45RO- cells ${ }^{6}$ which become CD45RO+ after anti-CD3CD28 stimulation (online supplemental figure $5 \mathrm{~B}$ ). The proliferative capacity of CD4+ CD45RO+CD161+ and CD161- cells after TCR stimulation was similar (figure 5A-B). TCR stimulation resulted in a dose-dependent decrease in percentage CD161+ cells and CD161 expression per cell (figure 5C-D, online supplemental figure $5 \mathrm{C}$ ). This was due to decreased transcription as KLRB1 levels were strongly declined at day 5 (figure $5 \mathrm{E}$ ). In contrast to CD161, the percentages of cells expressing the coinhibitory molecules PD1 and CD39 were increased after TCR stimulation and especially CD161+ sorted cell cultures contained higher percentages of CD39+ and PD1+ cells (figure 5C,F, online supplemental figure 5D). Furthermore, the percentage of stimulated cells expressing CD161 declined with each cell division at a linear rate (figure $5 \mathrm{G}-\mathrm{H}$ ). In contrast, the percentage PD1+ cells remained high for two divisions, but rapidly declined thereafter whereas the percentage 

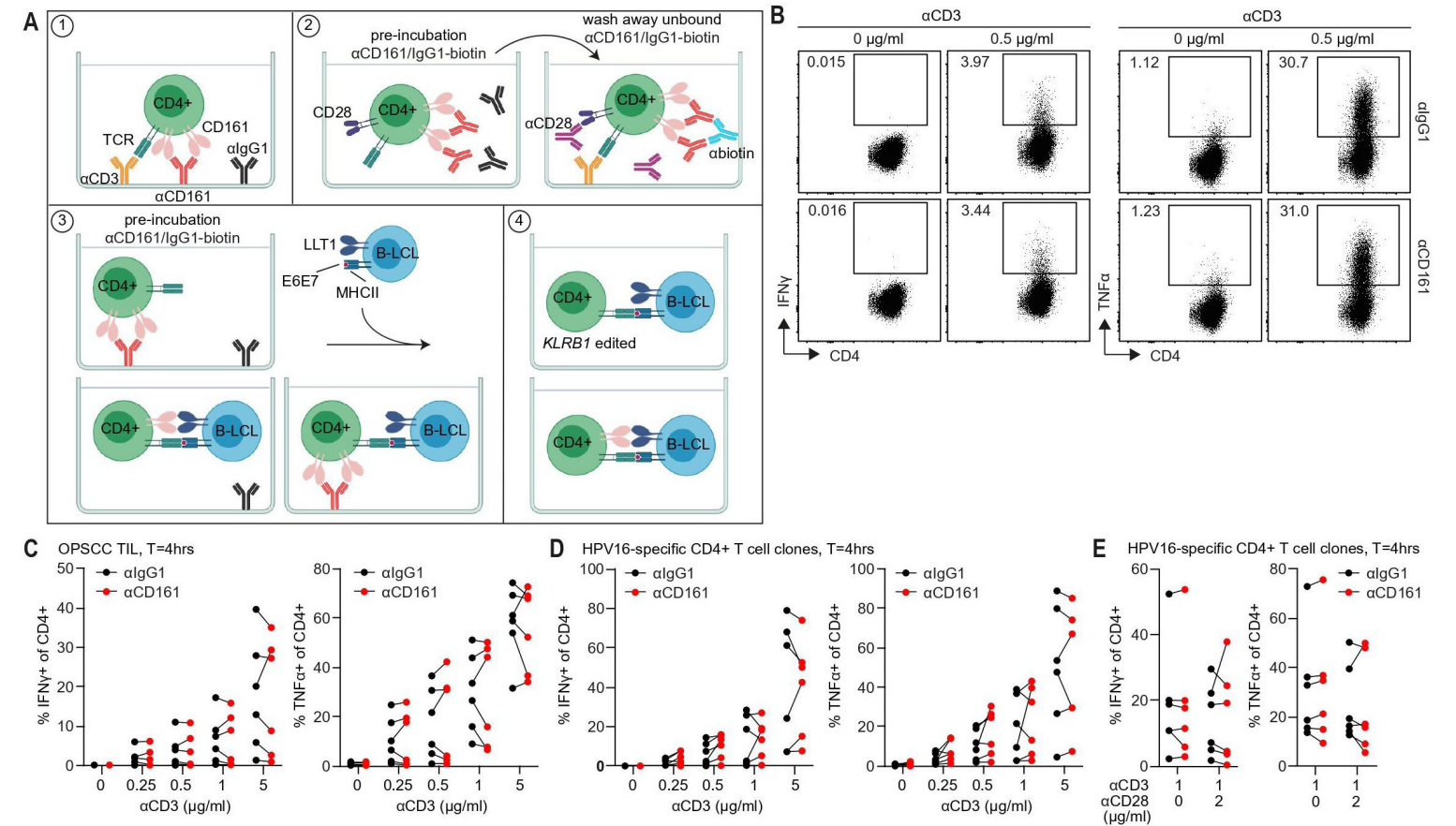

E HPV16-specific CD4+ $\mathrm{T}$ cell clones, $\mathrm{T}=4 \mathrm{~h}$ rs

D HPV16-specific CD4+ $\mathrm{T}$ cell clones, $\mathrm{T}=4 \mathrm{hrs}$
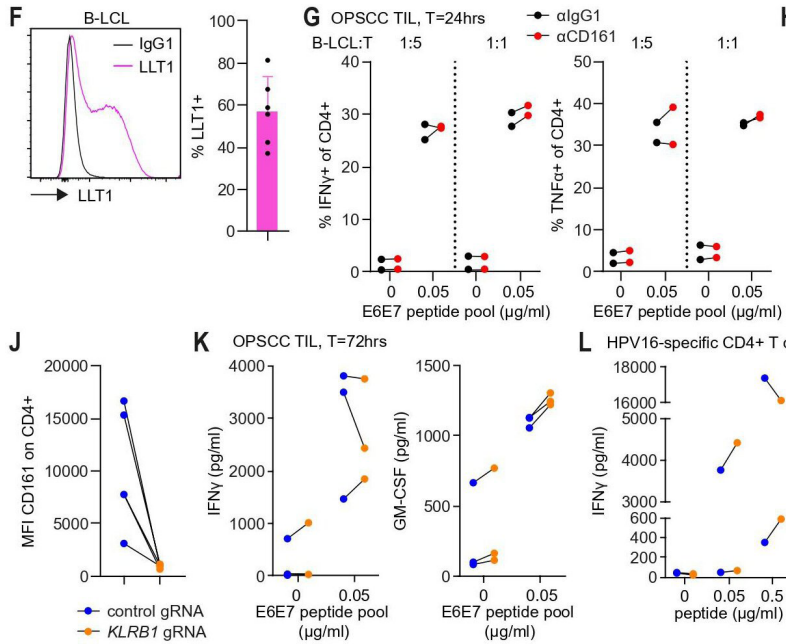

H OPSCC TIL, T=72hrs

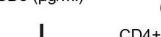

E HPV16-specific CD4+T cell clones,
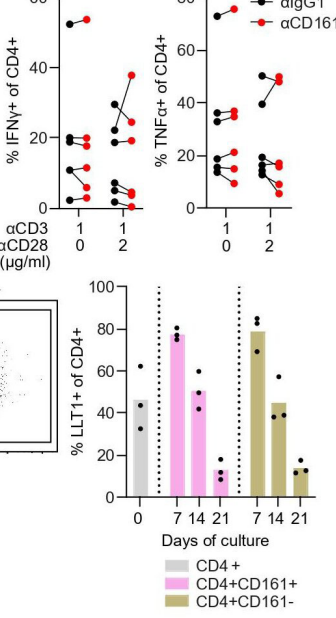

L HPV16-specific CD4+ $T$ cell clones, $T=72$ hrs

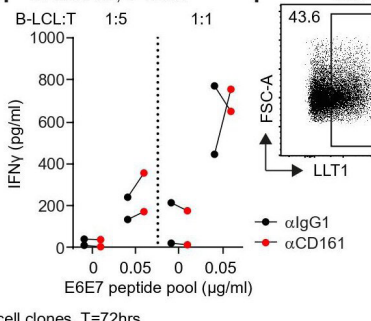

$\left.{ }^{18000}\right]$

CD4+CD $161+$
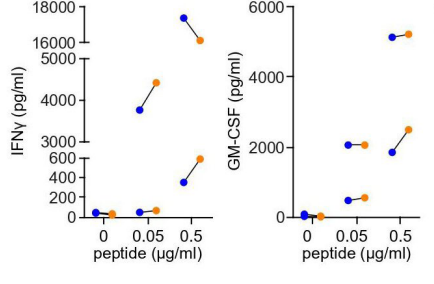

Figure 3 CD161 does not function as a checkpoint molecule on CD4+ T cells. (A) Graphical illustration of the four experimental approaches used to study the function of CD161. (\#1) Cells were stimulated with plate-bound anti-CD3 ( $\alpha C D 3$, clone UCHL1, indicated concentrations) and plate-bound anti-lgG1 ( $\alpha$ lgG1, clone MOPC-21) or anti-CD161 ( $\alpha \mathrm{CD} 161$, clone HP-3G10) (OPSCC TIL: $10 \mu \mathrm{g} / \mathrm{mL}$, HPV16-specific CD4+ T cell clones: $5 \mu \mathrm{g} / \mathrm{mL}$ ) for 4 hours. (\#2) Cells were preincubated with biotinylated anti-IgG1 (clone MOPC-21) or anti-CD161 (clone HP3G10) $(5 \mu \mathrm{g} / \mathrm{mL}$ ) for $30 \mathrm{~min}$, unbound antibodies were washed away followed by crosslinking with anti-biotin antibody during CD3-mediated TCR stimulation (plate-bound, $1 \mu \mathrm{g} /$ $\mathrm{mL}$ ) and CD28 ( $\alpha \mathrm{CD} 28$, clone CD28.2, $2 \mu \mathrm{g} / \mathrm{mL}$ ) costimulation for 4 hours. (\#3) Cells were preincubated with plate-bound antiIgG1 or anti-CD161 $(10 \mu \mathrm{g} / \mathrm{mL})$ before peptide-loaded LLT1 expressing B-LCL were added at a ratio B-LCL:T cell of 1:5 and $1: 1$ for 24 and 72 hours. (\#4) Control or KLRB1 edited cells (KLRB1 KO) were cocultured with peptide-loaded LLT1 expressing $B-L C L$ at a ratio B-LCL:T cell of 1:1 for 72 hours. This illustration was created with BioRender.com. (B-D) Representative dot plots and summary graphs showing percentage IFN $\gamma+$ and TNF $\alpha+$ of CD4+ cells upon stimulation of CD4+CD161+ TIL (B-C, $n=6)$ and HPV16-specific CD4+ T cell clones ( $D, n=6$ ) using approach 1. (E) Graphs show percentages IFN $\gamma+$ and TNF $\alpha+$ of CD4+ cells upon stimulation using approach $2(n=6)$. (F) Histogram overlay showing LLT1 staining and summary graph showing percentage LLT1+ cells on B-LCL generated from HPV16+IR+ OPSCC and cervical cancer patients $(n=6)$. (G) Summary graphs showing percentages IFN $\gamma+$ and TNF $\alpha+$ of CD4+ cells upon stimulation of CD4+CD161+ TIL for 24 hours using approach 3 $(n=2)$. (H) IFN $\gamma$ production upon stimulation of CD4+CD161+ TIL for 72 hours using approach $3(n=2)$. (I) Representative dot plot and summary graph showing percentage LLT1+ of CD4+ cells from OPSCC TIL on day 0 and during expansion culture of sorted CD4+CD161+ and CD161- cells $(n=3)$. Bar graph shows mean. $(J)$ Summary graph showing depletion of CD161 protein expression on CD4+ cells in KLRB1 edited cells compared to control $(\mathrm{n}=5)$. (K-L) IFN $\gamma$ and GM-CSF production by KLRB1 edited CD4+CD161+ TIL (K, $n=3)$ and HPV16-specific CD4+ T cell clones $(L, n=2)$ upon stimulation using approach 4. B-LCL, B lymphoblastoid cell lines; HPV16, human papillomavirus 16; IFN $\gamma$, interferon $\gamma$; IR+, immune response positive; LLT1, Lectin-like transcript 1; OPSCC, oropharyngeal squamous cell carcinoma; TCR, T cell receptor; TIL, tumor-infiltrating lymphocytes; TNF $\alpha$, tumor necrosis factor $\alpha$. 

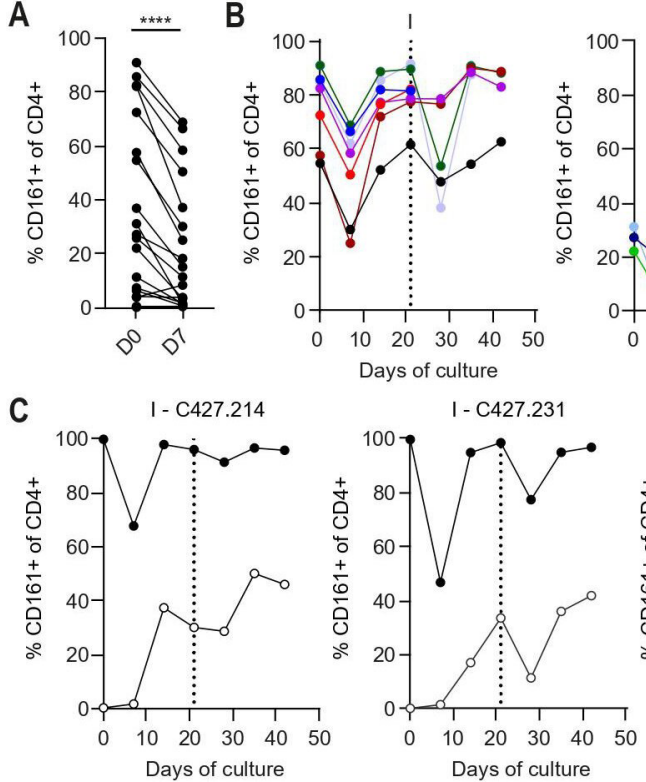

CDR3 peptide

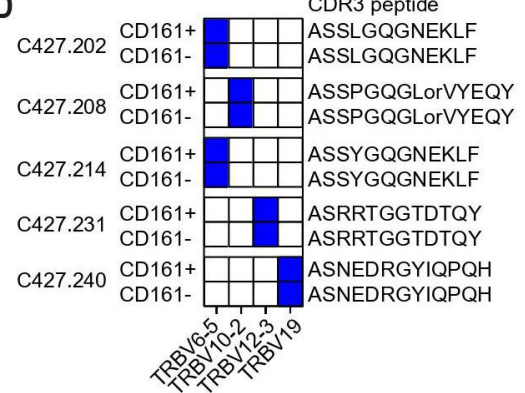

Figure 4 CD161 expression is dynamic upon TCR triggering and in time. HPV16-specific CD4+ T cell clones from HPV16+IR+ OPSCC $(n=7)$ and cervical cancer patients $(n=16)$ were expanded for 3 weeks. (A) Percentage CD161+ of CD4+ cells within CD4+ T cell clones on day 0 and day 7 of culture $(n=19)$. (B) Percentage CD161+ of CD4+ cells during culture of HPV16-specific T cell clones $(n=19)$ divided into 4 groups of CD161 expression patterns: I- $>50 \%$ CD161+ $(n=7), I I-20 \%-50 \%$ CD161+ $(n=3)$, III - <20\% CD161+ (n=3), IV - \% CD161+ increases over time $(n=6)$. Dotted line indicates re-stimulation of clones with their cognate peptide for another 3 weeks. (C, D) HPV16-specific CD4+ T cell clones $(n=5)$ belonging to group I $(n=2)$, II $(n=1)$ and III $(n=2)$ were sorted into CD161+ and CD161- T cell populations. (C) Sorted clones were cultured and percentage CD161+ T cells was monitored over time. Dotted line indicates re-stimulation of clones with their cognate peptide. (D) TRBV repertoire was determined on day of sort (day 0 of culture) for $\mathrm{CD} 4+\mathrm{CD} 161+$ and $\mathrm{CD} 161$ - cell populations of each sorted T cell clone using iRepertoire $(n=5) .{ }^{* \star \star \star} p<0.0001$. HPV16, human papillomavirus 16 ; IR+, immune response positive; OPSCC, oropharyngeal squamous cell carcinoma; TCR, T cell receptor; TRBV, T cell receptor beta variable.

CD39+ cells slowly increased with each division round within $\mathrm{CD} 161+$ sorted cells (figure $5 \mathrm{H}$ ). The strong decline in CD161/KLRB1 expression upon TCR stimulation and linear reduction in CD161 cell surface expression with cell division is different from the kinetics observed for PD1 and CD39 suggesting differences in cell surface protein stability. Therefore, CD4+ cells were cultured in presence of cycloheximide (CHX), which blocks protein translation, and expression of the different proteins was followed in time. While percentages of PD1+ and CD39+ cells were strongly reduced within 72 hours, the decline in percentage of CD161+ cells was much slower with only $50 \%$ reduction after 120 hours of culture (figure 5I). Thus, expression of CD161 is downregulated by TCR signaling at both mRNA and protein level, and its expression pattern is opposite to the known coinhibitory markers PD1 and CD39. This is consistent with our observation that CD161 does not function as a coinhibitory molecule in $\mathrm{CD} 4+$ cells.

\section{TGF $\beta 1$ regulates CD161 expression on CD4+ T cells}

Transforming growth factor beta (TGF $\beta$ ) expressing cells are present at variable levels in OPSCC (figure 6A-B). TGF $\beta$ is related to worse overall survival in OPSCC ${ }^{29}$ and known to increase expression of PD1, CD39 and CD103 $3^{3031}$ on T cells. To determine if TGF $\beta$ affects CD161 expression, healthy donor-derived CD4+CD45RO+CD161+ and CD161- cells were stimulated using anti-CD3CD28 beads in presence or absence of TGF $\beta 1$. An increased percentage of CD39+ and PD1+ cells was observed from day 7 of culture in the presence of anti-CD3CD28 stimulation and TGF $\beta 1$. The percentage of $\mathrm{CD} 103+$ cells was increased from 3 days onwards. This effect was independent of CD161 status (online supplemental figure 6A-B). In contrast, percentages of CD161+ cells 


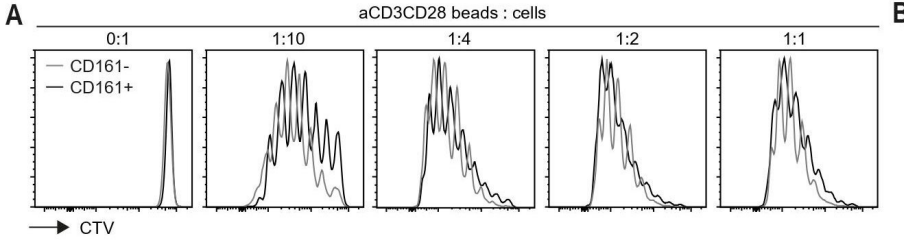

C $\quad$ aCD3CD28 beads : cells
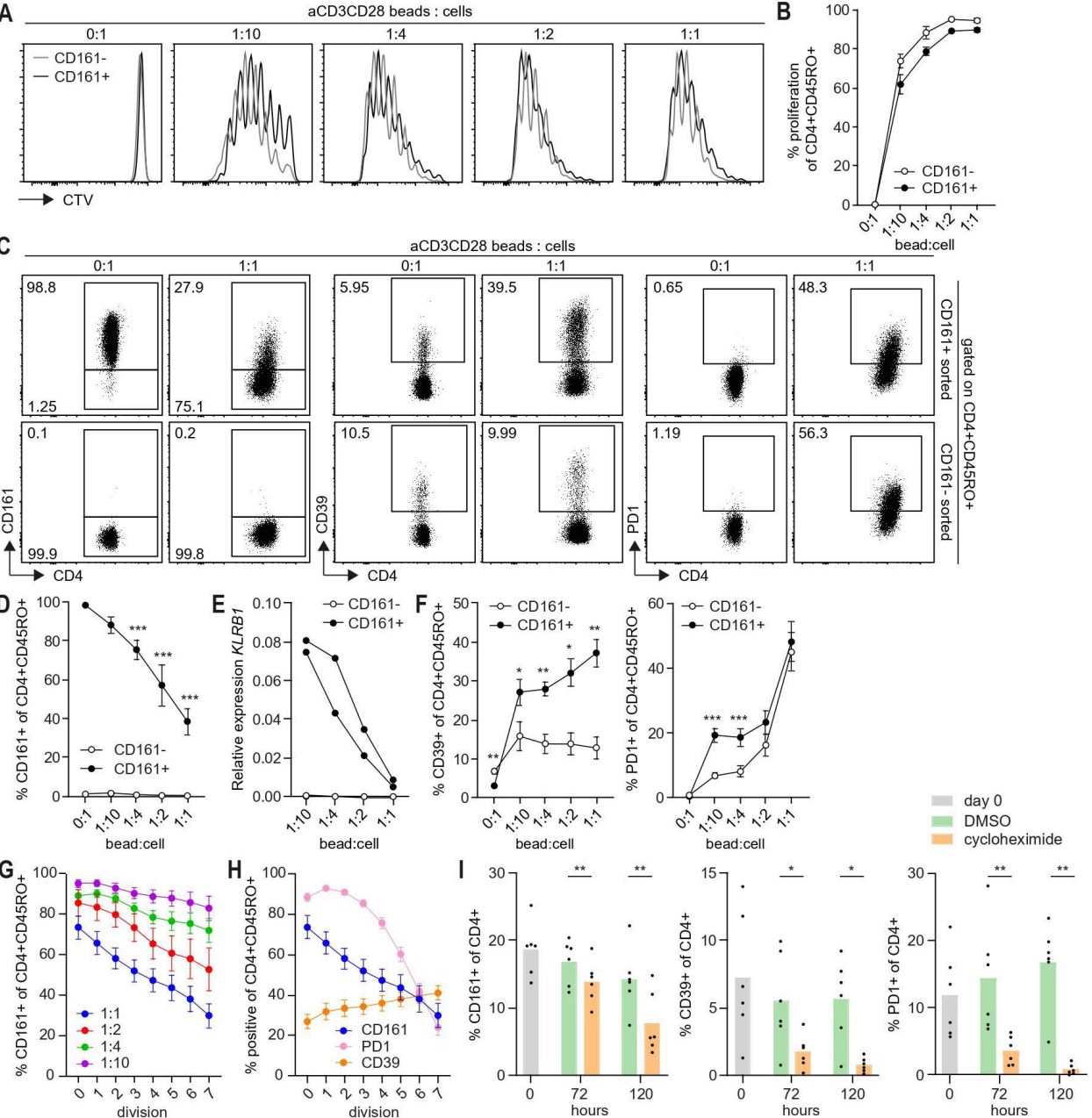

Figure 5 Downregulation of CD161 protein expression depends on TCR-signaling strength. (A-H) CD4+CD161+ and CD161cells were sorted from PBMC of adult healthy controls, labeled with CellTrace Violet (CTV) and stimulated for 5 days in presence of anti-CD3CD28 beads to cell ratio (bead:cell) as indicated ( $n=5-9$ unless otherwise indicated). Summary data represent mean \pm SEM. (A) Representative histogram overlays for CD4+CD45RO+CD161+ and CD161-cells showing CTV dilution for anti-CD3CD28 stimulation as indicated. (B) Summary graph showing percentage proliferation of CD4+CD45RO+CD161+ and CD161- cells upon stimulation with anti-CD3CD28. (C) Representative dot plots showing percentage CD161+, CD39+ and PD1+ cells within CD4+CD161+ and CD161- cultures gated on CD4+CD45RO+ cells for anti-CD3CD28 beads to cell ratio as indicated. (D) Summary graph showing percentage CD161+ cells within CD4+CD161+ and CD161- cultures cells gated on CD4+CD45RO+ cells after TCR stimulation. Significance was analyzed for bead:cell of 1:10-1:1 compared to 0:1. (E) Relative expression of KLRB1 (CD161) within CD4+CD161+ and CD161- cultures after 5 days of TCR stimulation ( $\mathrm{n}=2)$. (F) Summary graph showing percentage CD39+ and PD1+cells within CD4+CD161+ and CD161- cultures gated on CD4+CD45RO+ cells after TCR stimulation. Significance was analyzed for CD161+ compared to CD161- cells. (G) Percentage CD161+ of CD4+CD45RO+ cells within CD4+CD161+ culture per division after stimulation with anti-CD3CD28 beads to cell ratio as indicated. (H) Percentage CD161+, CD39+ and PD1+ cells within CD161+ cultures gated on CD4+CD45RO+ cells per division for anti-CD3CD28 beads to cell ratio of 1:1. (I) CD4+ cells from adult healthy controls were cultured in presence of $20 \mu \mathrm{g} / \mathrm{mL}$ cycloheximide (CHX) or DMSO vehicle control for 72 and 120 hours and analyzed for percentage CD161+, CD39+ and PD1+ of CD4+ cells $(n=6)$. Summary data represent mean \pm SEM. ${ }^{*} p<0.05$, ${ }^{* *} p<0.01,{ }^{* * *} \mathrm{p}<0.001$. DMSO, dimethyl sulfoxide; $K L R B 1$, killer cell lectin-like receptor B1; PBMC, peripheral blood mononuclear cells; TCR, T cell receptor.

decreased when TGF $\beta 1$ was present (figure 6C-E). TGF $\beta 1$ had no effect on $\mathrm{T}$ cell activation as indicated by CD154 expression (figure 6F, online supplemental figure 6C). The observed effect was TGF $\beta 1$ specific as it was reversed by addition of SB505124, a selective inhibitor of TGF $\beta$ type I receptor (like) kineases, i.e. activin receptor-like kinase (ALK) 4, ALK5 and ALK7 signaling, to sorted CD4+CD45RO+CD161+ cells (figure 6G-H, online supplemental figure 6D) or addition of a pan-neutralizing TGF $\beta$ antibody to CD4+ cells (online supplemental figure 7A-B). Notably, proliferation of cells was not affected by TGF 31 or SB505124 (figure 6I). The effect of TGF $\beta 1$ tapped into regulation of CD161 at gene level as $K L R B 1$ expression was decreased after 5 days to about $60 \%$ without anti-CD3CD28 stimulation and 80\%-90\% with antiCD3CD28 stimulation (figure 6J). We confirmed the effect of TGF 31 on CD161, PD1 and CD103 for HPV16-specific $\mathrm{CD} 4+\mathrm{CD} 161+\mathrm{T}$ cell clones stimulated with different doses of cognate antigen (figure 6K, online supplemental figure 

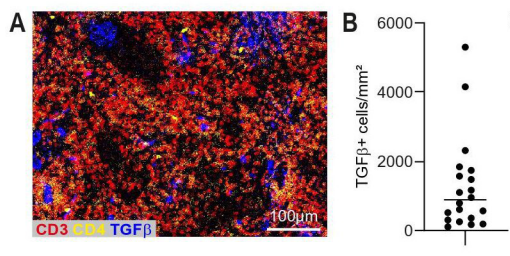

C day $7-\mathrm{CD} 4+\mathrm{CD} 45 \mathrm{RO}+\mathrm{CD} 161+$
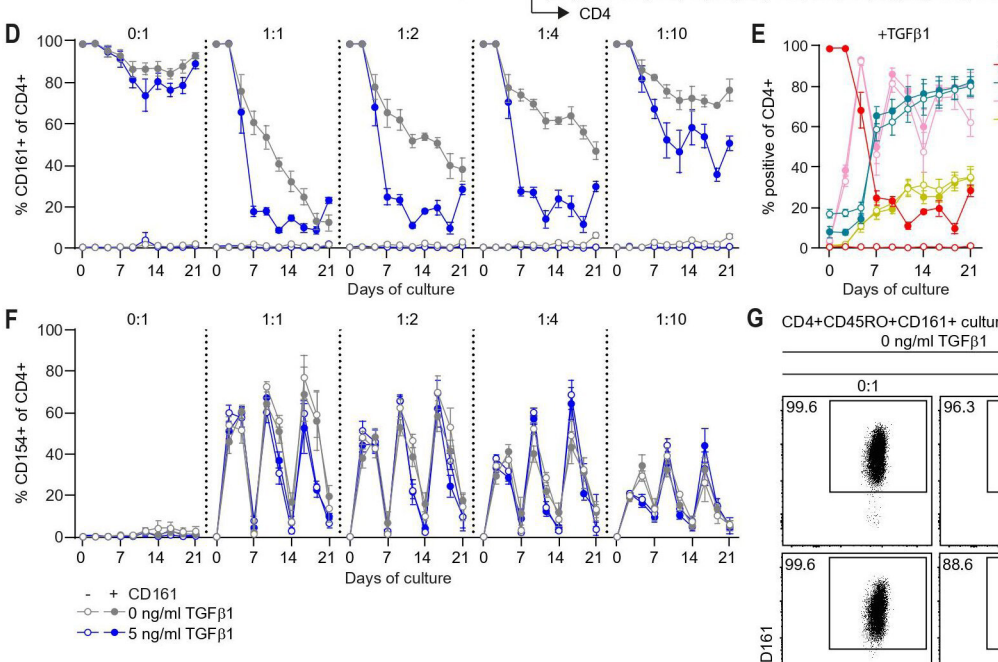

G $\mathrm{CD} 4+\mathrm{CD} 45 \mathrm{RO}+\mathrm{CD} 161+$ culture
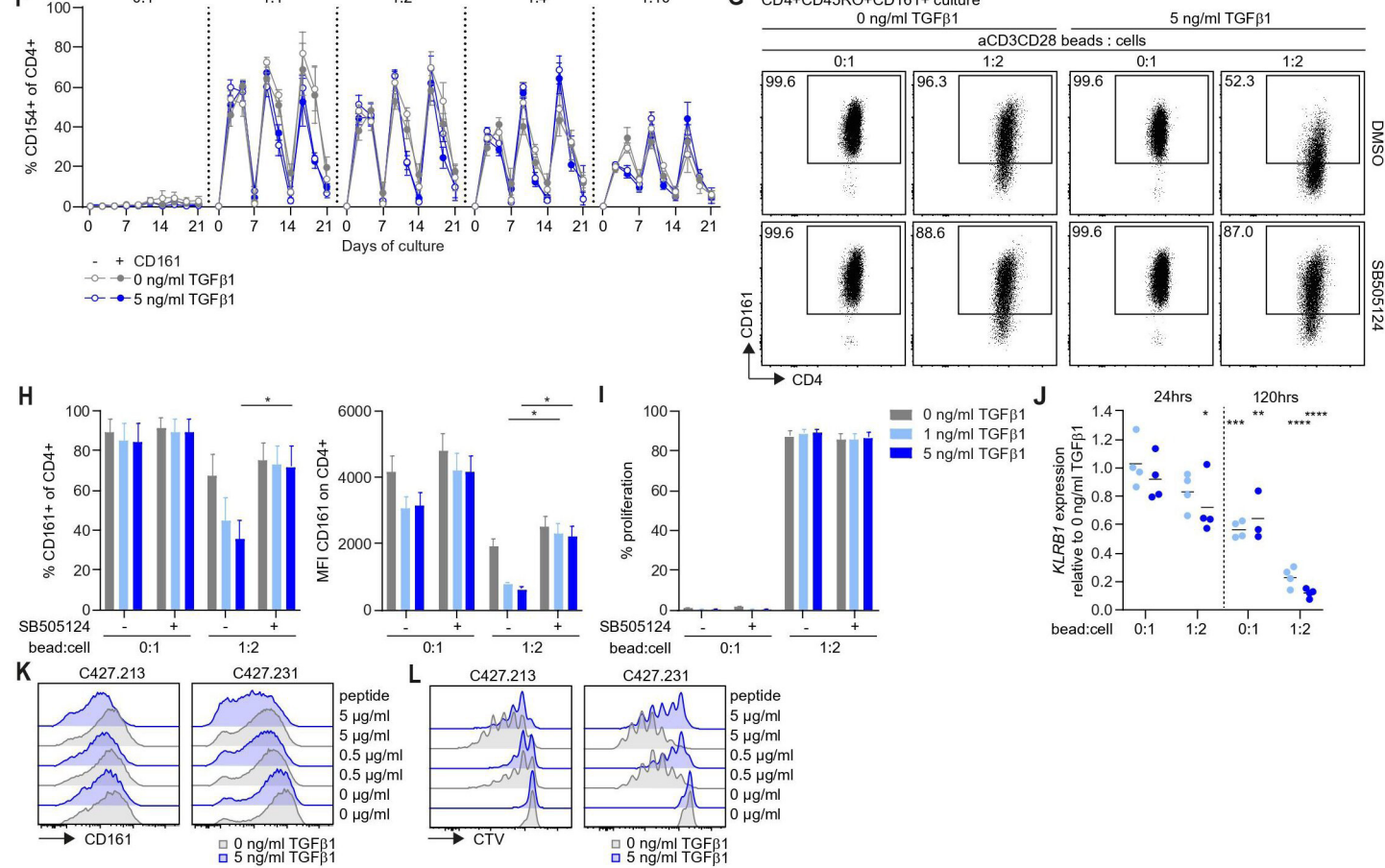

C427.231

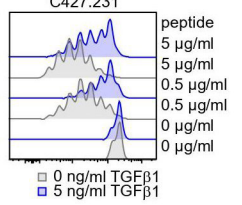

Figure 6 TGF $\beta 1$ reduces CD161 expression on CD4+ T cells. (A) FFPE tumor tissue of OPSCC patients was analyzed by imaging mass cytometry for CD3 (red), CD4 (yellow) and TGF $\beta$ (blue) expression. A representative example of staining in a HPV $16+I R+$ sample is shown. (B) TGF $\beta+$ cells $/ \mathrm{mm}^{2}$ in tumor tissue sections of OPSCC patients as determined by imaging mass cytometry. Line indicates median. (C-F) CD4+CD45RO+CD161+ and CD161- cells were sorted from PBMC of adult healthy controls and cultured in presence of 0 or $5 \mathrm{ng} / \mathrm{mL} \mathrm{TGF} \beta 1,5 \mathrm{ng} / \mathrm{mL}$ rhlL-7 and anti-CD3CD28 beads at bead to cell ratio as indicated $(n=3-5)$. Cells were restimulated with anti-CD3CD28 beads every 7 days and medium containing TGF $\beta 1$ and rhIL-7 was refreshed every 3-4 days. Graphs show mean \pm SEM. (C) Representative dot plots showing percentage CD161+ of CD4+ cells within the CD4+CD161+ culture in presence or absence of TGF $\beta 1$ and anti-CD3CD28 beads as indicated on day 7 of culture. (D) Percentage CD161+ of CD4+ cells within CD4+CD161+ and CD161- cultures in time. (E) Percentage CD161+, CD39+, PD1+, CD103+ of CD4+ cells upon stimulation with anti-CD3CD28 beads to cell ratio of 1:2 and $5 \mathrm{ng} / \mathrm{mL}$ TGFß1.

(F) Percentage CD154+ of CD4+ cells within CD4+CD161+ and CD161- cultures in time. (G-J) CD4+CD45RO+CD161+ cells were sorted from PBMC of adult healthy controls, labeled with CTV and cultured in presence of $0,1 \mathrm{or} 5 \mathrm{ng} / \mathrm{mL} \mathrm{TGF} \beta 1,5 \mathrm{ng} /$

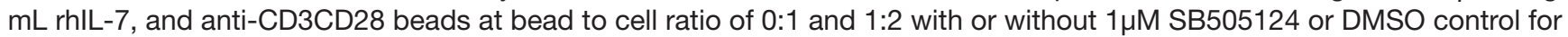
5 days as indicated $(n=5$ unless otherwise indicated). (G) Representative dots plots showing percentage CD161+ cells within CD4+CD161+ cultures. (H, I) Percentage CD161+ of CD4+ cells, MFI CD161 on CD4+ cells (H), and percentage proliferation (I) within CD4+CD161+ cultures. Graphs show mean \pm SEM. (J) KLRB1 expression in CD4+CD161+ cultures stimulated with 1 and $5 \mathrm{ng} / \mathrm{mL}$ TGF $\beta 1$ relative to $0 \mathrm{ng} / \mathrm{mL}$ TGF $\beta 1$ with or without anti-CD3CD28 beads after 24 hours and 120 hours $(n=3-4)$. Lines indicate mean and significance was analyzed compared to $0 \mathrm{ng} / \mathrm{mL}$ TGF $\beta 1$. (K, L) Two HPV16-specific CD4+ T cell clones were labeled with CTV and stimulated with $5 \mathrm{ng} / \mathrm{mL}$ rhIL-15, peptide-loaded B-LCL with or without $5 \mathrm{ng} / \mathrm{mL}$ TGF $\beta 1$ for 5 days. Histograms show CD161 protein expression $(K)$ and CTV dilution $(L)$ for indicated stimuli. ${ }^{*} p<0.05,{ }^{* *} p<0.01,{ }^{* * *} p<0.001$, ${ }^{\star \star \star \star} \mathrm{p}<0.0001$. B-LCL, B lymphoblastoid cell lines; CTV, CellTrace Violet; FFPE, formalin-fixed paraffin-embedded; HPV16, human papillomavirus 16; IR+, immune response positive; KLRB1, killer cell lectin-like receptor B1; OPSCC, oropharyngeal squamous cell carcinoma; MFI, median fluorescence intensity; PBMC, peripheral blood mononuclear cells; rhIL-7, recombinant human interleukin-7; rhIL-15, recombinant human interleukin-15; TGF $\beta 1$, transforming growth factor $\beta 1$. 
$6 \mathrm{E})$. However, TGF $\beta 1$ reduced proliferation and the effect on CD39 was minimal because expression levels were already high (figure 6L, online supplemental figure 6E).

Other members of the TGF $\beta$ family, such as Activin A, and bone morphogenetic protein (BMP) 2 and BMP6 that signal via distinct surface receptors, had no effect on CD161 indicating that the observed effect is specific for TGF $\beta 1$. Activin A did increase the percentages of CD39+, PD1+ and CD103+ cells, consistent with published data for CD39 and PD1, ${ }^{33}$ and the effect was reversed by SB505124 (online supplemental figure 8).

Thus, the effect of TGF $\beta 1$ on expression of CD161 is different from the effect on well-known coinhibitory molecules and not part of general T cell suppression, because activation and proliferation of cells was not affected.

\section{CD4+CD161+ cells specifically express the transcriptional transactivator SOX4}

The observation that CD161 expression is dynamically regulated at gene level after TCR signaling (figure 5E) and expressed on $\mathrm{CD} 4+$ cells with different cytokine patterns suggests that CD161 expression by CD4+ cells is likely to reflect an activation state of cells ${ }^{34}$ in human tumors. This would imply that CD161 expression can be found among different $\mathrm{T}$ cell clusters in tumors and is associated with expression of particular transcription factors. Unsupervised clustering of CD3+ cells from our single-cell RNA sequencing data of OPSCC patients ${ }^{35}$ (Abdulrahman et al submitted) identified 29 different CD3+ clusters of which 11 clusters were CD4+ (figure 7A). Analysis of KLRB1 expression revealed that it is expressed by multiple CD4+ clusters (figure 7B,C). Similar analysis using publicly available single-cell RNAseq datasets for NSCLC, ${ }^{24} \mathrm{CRC}^{25}$ and $\mathrm{HCC}^{26}$ confirmed our findings (figure 7D).

Transcriptional profiling of CD27-CD161- stage 1 and CD27+CD161+ stage 3 mucosal associated invariant T (MAIT) cells highlighted differential expression of several transcription factors including BACH2, EOMES, SATB1, LEF1, TCF7 (TCF1), SOX4 and RUNX3. ${ }^{36}$ As expected, expression of $\mathrm{BACH} 2$, a transcriptional repressor of memory/effector cells, ${ }^{37}$ was low after anti-CD3CD28 stimulation of blood-derived CD4+CD161+ and CD161- cells. There was no difference in expression of EOMES, involved in type 1 commitment, ${ }^{38}$ and $S A T B 1$, a regulator of lineage-specific genes, ${ }^{39}$ between CD4+CD161+ and CD161- cells (figure 7E, online supplemental figure 9A). The transcription factors $L E F 1, T C F 7$ and SOX4 are known to function as T cell enhancers. ${ }^{40} 41$ There was no difference in expression of $L E F 1$ and TCF7 between CD4+CD161+ and CD161- cells upon TCR stimulation, but SOX4 was exclusively expressed in CD161+ cells (figure 7E, online supplemental figure 9A). In contrast to CD4+CD161+ cells, not all CD4+CD161- cells display a memory phenotype after stimulation (online supplemental figure 5B). If SOX4 expression would simply reflect memory $\mathrm{T}$ cells, expression would not be absent in CD4+CD161- cells, but detected at lower levels. Similar to our observations for KLRB1/CD161, expression of SOX4 was reduced upon increasing strength of TCR activation (figure $7 \mathrm{~F}$ ). In line with this, exposure to TGF $\beta 1$ had no effect on $L E F 1$ and TCF7 expression, but further reduced expression of SOX4 in a dose-dependent manner (figure 7G, online supplemental figure 9B). Thus, the expression of $K L R B 1 / \mathrm{CD} 161$ is coregulated with the $\mathrm{T}$ cell enhancer SOX4 by cell intrinsic and extrinsic factors associated with $\mathrm{T}$ cell activation.

Based on the coregulation of KLRB1/CD161 and the $\mathrm{T}$ cell enhancer SOX4, we hypothesized that CD161 expression may reflect an enhanced activation state. To examine this, HPV16-specific CD4+ T cell clones were stimulated with cognate antigen in presence of rhIL-12 and rhIL-18, previously shown to act on CD161+ T cells. ${ }^{842}$ Our data show that these cytokines improved the reactivity of both CD4+CD161+ and CD161- populations. However, under limiting amounts of antigen, the percentage of $\mathrm{T}$ cells producing IFN $\gamma$ was significantly higher among the CD161+ population compared to their CD161- counterparts (figure $7 \mathrm{H}$ ). Thus, these data suggest that CD161 expression by CD4+ cells reflects a specific activation state allowing these cells to respond more vigorously.

\section{DISCUSSION}

In this study, we demonstrated that the TME of HPV16+IR+ OPSCC is highly infiltrated by CD4+CD161+ and CD8+CD161+ Tem. While expression of CD161 did not alter the impact of CD8+ cells on survival, there was a clear clinical benefit when tumors were infiltrated with relatively high numbers of CD4+CD161+ Tem. This suggests that mainly CD4+CD161+ cells contribute to the prognostic impact and improved survival associated with high KLRB1 expression levels in tumors. ${ }^{23}{ }^{2344} \mathrm{CD} 4+\mathrm{CD} 161+$ cells display a stronger type 1 response to suboptimal antigen stimulation (this study) and produce more cytokines at a per cell basis upon antigen stimulation. ${ }^{2}$ The stronger reactivity of these cells might be due to a concerted action between the transcriptional transactivator SOX4, which transactivates $\mathrm{CD} 3 \varepsilon,{ }^{41}$ enhances TCR signaling ${ }^{45}$ and is specifically expressed by CD4+CD161+ cells, and CD161, which interacts with acid sphingomyelinase to generate ceramide required for the signaling cascade downstream of CD3. ${ }^{47}$

The role of CD161 as a costimulatory or coinhibitory molecule is highly debated and the outcomes varied depending on the experimental setup used. Many studies examined CD161 function using plate-bound antibodies or beads coated with anti-CD3 and/or anti-CD28 to stimulate T cells, or LLT1+ cell lines. ${ }^{8121315-17}$ The most compelling evidence for a coinhibitory function of CD161 on CD8+ cells came from a study in which KLRB1 expression was knocked-out in NY-ESO-1 TCR transduced T cells. ${ }^{10}$ We used HPV16-specific CD4+CD161+ cells in all these experimental approaches, but found no consistent coinhibitory or costimulatory effect. One of the problems with CD161-specific antibody blockade could be that activated $\mathrm{T}$ cells express LLT $1^{12}$, hence LLT1 can directly interact 

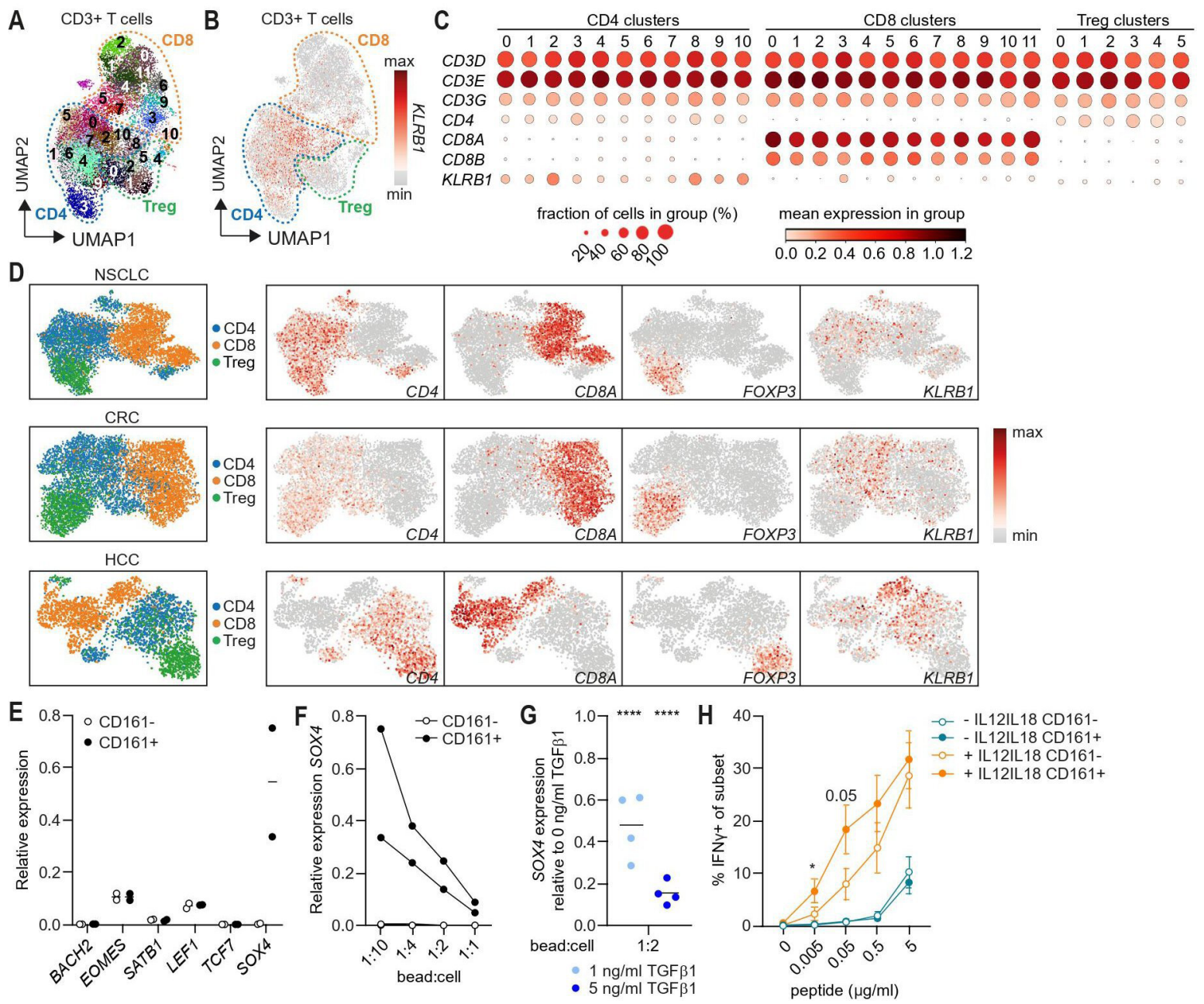

Figure 7 CD161+CD4+ T cells specifically express the transcriptional transactivator SOX4. (A-C) Ex vivo TIL samples from OPSSC patients were enriched for CD3+CD56+ cells and analyzed by single-cell RNAseq $(n=13)$. Clustering analysis was restricted to CD3+ cells. (A) Two-dimensional UMAP plot showing 29 different CD3+ clusters identified using the Leiden algorithm. These CD3+ clusters could be further divided into 11 CD4+, 12 CD8+ and 6 Treg clusters. (B) Two-dimensional UMAP plot showing distribution of KLRB1 expression. (C) Plot showing fraction of cells in group (\%) and mean expression in group for $C D 3 D, C D 3 E, C D 3 G, C D 4, C D 8 A, C D 8 B$ and $K L R B 1$. (D) Single-cell RNAseq analysis of published datasets for NSCLC, ${ }^{24} \mathrm{CRC},{ }^{25} \mathrm{HCC}^{26}$ showing CD4, CD8 and Treg clusters (left) and distribution of CD4, CD8A, FOXP3, KLRB1 (CD161) expression (right). (E, F) CD4+CD161+ and CD161- cells were sorted from PBMC of adult healthy controls and stimulated for 5 days in presence of anti-CD3CD28 beads to cell ratio (bead:cell) as indicated $(n=2)$. ( $E$ ) Summary graph showing relative expression of BACH2, EOMES, SATB1, LEF1, TCF7 and SOX4 upon stimulation of CD4+CD161+ and CD161- cells with bead:cell ratio of 1:10. Line indicates mean. (F) Summary graph showing relative expression of SOX4 within CD4+CD161+ and CD161- cultures after 5 days of stimulation with anti-CD3CD28 beads. (G) CD4+CD45RO+CD161+ cells were sorted from PBMC of adult healthy controls and cultured in presence of 0,1 or $5 \mathrm{ng} / \mathrm{mL}$ TGF $\beta 1$ and anti-CD3CD28 beads at bead to cell ratio of 1:2 for 5 days. Graph showing SOX4 expression relative to $0 \mathrm{ng} / \mathrm{mL}$ TGF $\beta 1$ after 120 hours $(n=4)$. Lines indicate mean and significance was analyzed compared to $0 \mathrm{ng} / \mathrm{mL}$ TGF $\beta 1$. (H) Percentage IFN $\gamma+$ of CD4+CD161+ or CD161- cells upon stimulation of 17 different HPV16-specific CD4+ T cell clones with peptide-loaded B-LCL with or without $50 \mathrm{ng} / \mathrm{mL}$ rhIL-12 and $50 \mathrm{ng} / \mathrm{mL}$ rhIL-18 for 24 hours with Brefeldin A added for the last 4 hours. Graph shows mean \pm SEM. ${ }^{*} \mathrm{p}<0.05,{ }^{* * * *} \mathrm{p}<0.0001$. CRC, colorectal cancer; HCC, hepatocellular carcinoma; KLRB1, killer cell lectin-like receptor B1; NSCLC, non-small cell lung cancer; OPSSC, oropharyngeal squamous cell carcinoma; PBMC, peripheral blood mononuclear cells; rhIL-12, recombinant human interleukin-12; rhIL-18, recombinant human interleukin-18; TGF $\beta 1$, transforming growth factor $\beta 1$; TIL, tumor infiltrating lymphocytes; UMAP, uniform manifold approximation and projection.

with CD161 and thereby prevent antibody binding. We used KLRB1 edited T cells to overcome this hurdle, but again no costimulatory or coinhibitory role for CD161 on CD4+ cells was found.

In contrast to increased expression of known checkpoint molecules PD1 and CD39 after T cell activation, expression of CD161 is reduced at both mRNA and protein level. While it is known that TGF $\beta 1$ induces expression of CD39, PD1 and CD103 on T cells, ${ }^{30}{ }^{31}$ we show here that costimulation with TGF $\beta 1$, but not other TGF $\beta$ superfamily members, resulted in an even stronger reduction of CD161 expression. The observed expression 
pattern of CD161 on CD4+ cells being the opposite of well-known checkpoints also argues against a coinhibitory function of CD161.

We demonstrated that more HPV16-specific CD4+CD161+ cells produced IFN $\gamma$ after suboptimal antigen and cytokine stimulation compared to their CD161- counterparts. This is consistent with a report showing that CD4+CD161+ TIL in NSCLC are more activated. ${ }^{43}$ These findings suggest that CD161 is a marker of a specific activation state of CD4+ cells in which cells are more prone to produce type 1 cytokines upon lowdose antigen encounter. In this context, expression of the T cell enhancers LEF1, TCF7 (TCF-1) and SOX4 is of interest. As expected, expression of $L E F 1$ and TCF7, both important for TCR $\alpha$ gene expression, did not differ between CD4+CD161+ and CD161- cells. SOX4, which transactivates CD $3 \varepsilon$ and enhances TCR signaling, ${ }^{41} 4546$ shows higher expression in CD4+CD161+ cells. Similar to CD161, SOX4 expression was reduced upon TCR stimulation and TGF $\beta 1$ exposure. Although more research is required to understand the exact role of SOX 4 and CD161 in CD4+ cells, it seems that both amplify TCR signals via CD3. ${ }^{45-47}$

In conclusion, relatively high levels of CD4+CD161+ Tem are associated with better clinical outcome. These cells respond more vigorously to TCR stimulation under suboptimal conditions fostered by their responsiveness to innate cytokines ${ }^{842}$ and expression of TCR-signaling amplifying molecules SOX4 and potentially CD161 itself. Cytokine-producing CD4+CD161+ effector cells can be induced by therapeutic vaccination, but as TGF $\beta 1$ downregulates both $K L R B 1 / \mathrm{CD} 161$ and SOX4, immunotherapeutic strategies may include TGF $\beta$ inhibition.

\section{Author affiliations}

${ }^{1}$ Department of Medical Oncology, Oncode Institute, Leiden University Medical Center, Leiden, The Netherlands

${ }^{2}$ Biocenter, Institute of Bioinformatics, Medical University of Innsbruck, Innsbruck, Austria

${ }^{3}$ Department of Immunology, Leiden University Medical Center, Leiden, The Netherlands

${ }^{4}$ Department of Gynecology, Leiden University Medical Center, Leiden, The Netherlands

${ }^{5}$ Institute of Molecular Biology, University of Innsbruck, Innsbruck, Austria ${ }^{6}$ Digital Science Center (DiSC), University of Innsbruck, Innsbruck, Austria ${ }^{7}$ Department of Cell and Chemical Biology, Leiden University Medical Center, Leiden, The Netherlands

${ }^{8}$ Institut de Pharmacologie Moléculaire et Cellulaire, Centre National de la Recherche Scientifique, Université Côte d'Azur, UMR7275, 06560 Valbonne, Sophia Antipolis, France

Acknowledgements We thank all the patients and healthy individuals who participated in this study.

Contributors Concept and study design: CLD, SJS, MJPW and SHvdB; acquisition of data: CLD, SJS, ZA, NML, THW, SB and IE; analysis and interpretation of data: CLD, SJS, ZA, GS, THW, RA, FF, HH, ZT, PtD, VMB, MJPW, SHvdB; patient management: MIEvP; writing original draft: CLD and SHvdB; review and editing: all; SHvdB is the guarantor of the study and accepts full responsibility for the work and/ or the conduct of the study, had access to the data, and controlled the decision to publish.

Funding CLD and NML are supported by a grant from the Dutch Cancer Society (2017-10726) to SJS, MJPW and SHvdB. SJS and IE are supported by a grant from the Dutch Cancer Society (2016-10168) to SHvdB. SHvdB has received base funding from the Oncode Institute. ZA has received an $\mathrm{MD} / \mathrm{PhD}$ grant from Leiden University Medical Center. FF was supported by the Austrian Science Fund (FWF) (project No. T974-B30) and by the Oesterreichische Nationalbank (OeNB) (project No. 18496). ZT was supported by the European Research Council (grant agreement No 786295) and by the Austrian Science Fund (FWF) (project I3978). ZT is a member of the German Research Foundation (DFG) project TRR 241(INF).

Competing interests GS reports personal fees from Pieris Pharmaceuticals GmbH outside the submitted work. FF has received honoraria for lecturing at the ESMO Virtual Advanced Course on Biomarkers for Precision Medicine 2021. PtD reports grants from Oncode Institute and Cancer Genomics Center Netherlands (CGC.NL). VMB reports funding from Centre National de la Recherche Scientifique, French Government (National Research Agency, ANR) through the 'Investments for the Future' programs LABEX SIGNALIFE ANR-11-LABX-0028 and IDEX UCAJedi ANR15-IDEX-01, Cancéropole PACA and Fondation ARC pour la recherche sur le Cancer SHvdB reports grants from 10 Biotech and DC Prime for immunemonitoring of trials and personal consulting fees from ISA Pharmaceuticals, PCI Biotech, DC Prime, CHDR consultancy services and AGLAIA outside the submitted work. The other authors declare no conflict of interest.

\section{Patient consent for publication Not applicable.}

Ethics approval Patients included in this study were part of studies investigating cellular immunity in head and neck and anogenital cancer (P07-112 and P08197) performed in accordance with the Declaration of Helsinki and approved by the medical ethical committee of Leiden University Medical Center (LUMC). The materials were used in accordance with the Dutch Federation of Medical Research Association guidelines. Participants gave informed consent to participate in the study before taking part.

Provenance and peer review Not commissioned; externally peer reviewed.

Data availability statement All data relevant to the study are included in the article or uploaded as online supplemental information. Data are also available from the corresponding author upon reasonable request.

Supplemental material This content has been supplied by the author(s). It has not been vetted by BMJ Publishing Group Limited (BMJ) and may not have been peer-reviewed. Any opinions or recommendations discussed are solely those of the author(s) and are not endorsed by BMJ. BMJ disclaims all liability and responsibility arising from any reliance placed on the content. Where the content includes any translated material, BMJ does not warrant the accuracy and reliability of the translations (including but not limited to local regulations, clinical guidelines, terminology, drug names and drug dosages), and is not responsible for any error and/or omissions arising from translation and adaptation or otherwise.

Open access This is an open access article distributed in accordance with the Creative Commons Attribution 4.0 Unported (CC BY 4.0) license, which permits others to copy, redistribute, remix, transform and build upon this work for any purpose, provided the original work is properly cited, a link to the licence is given, and indication of whether changes were made. See https://creativecommons.org/ licenses/by/4.0/.

\section{ORCID iDs}

Chantal L Duurland http://orcid.org/0000-0002-4063-8549

Saskia J Santegoets http://orcid.org/0000-0002-2874-4402

Ziena Abdulrahman http://orcid.org/0000-0001-9079-0293

Ramon Arens http://orcid.org/0000-0001-5058-4110

Francesca Finotello http://orcid.org/0000-0003-0712-4658

Hubert Hackl http://orcid.org/0000-0003-4055-3841

Veronique M Braud http://orcid.org/0000-0001-8213-3947

Sjoerd H van der Burg http://orcid.org/0000-0002-6556-0354

\section{REFERENCES}

1 Otter S, Whitaker S, Chatterjee J, et al. The human papillomavirus as a common pathogen in oropharyngeal, anal and cervical cancers. Clin Oncol 2019;31:81-90.

2 Santegoets SJ, van Ham VJ, Ehsan I, et al. The anatomical location shapes the immune infiltrate in tumors of same etiology and affects survival. Clin Cancer Res 2019;25:240-52.

3 Welters MJP, Ma W, Santegoets SJAM, et al. Intratumoral HPV16specific T cells constitute a type I-oriented tumor microenvironment to improve survival in HPV16-driven oropharyngeal cancer. Clin Cancer Res 2018;24:634-47. 
4 Lanier LL, Chang C, Phillips JH. Human NKR-P1A. A disulfide-linked homodimer of the C-type lectin superfamily expressed by a subset of NK and T lymphocytes. J Immunol 1994;153:2417-28.

5 Giorda R, Rudert WA, Vavassori C, et al. NKR-P1, a signal transduction molecule on natural killer cells. Science 1990;249:1298-300.

6 Takahashi T, Dejbakhsh-Jones S, Strober S. Expression of CD161 (NKR-P1A) defines subsets of human CD4 and CD8 T cells with different functional activities. J Immunol 2006;176:211-6.

7 Cosmi L, De Palma R, Santarlasci V, et al. Human interleukin 17 -producing cells originate from a CD161+CD4+ T cell precursor. J Exp Med 2008;205:1903-16.

8 Fergusson JR, Smith KE, Fleming VM, et al. CD161 defines a transcriptional and functional phenotype across distinct human $T$ cell lineages. Cell Rep 2014:9:1075-88.

9 Germain C, Guillaudeux T, Galsgaard ED, et al. Lectin-like transcript 1 is a marker of germinal center-derived B-cell non-Hodgkin's lymphomas dampening natural killer cell functions. Oncoimmunology 2015;4:e1026503.

10 Mathewson ND, Ashenberg O, Tirosh I, et al. Inhibitory CD161 receptor identified in glioma-infiltrating $\mathrm{T}$ cells by single-cell analysis. Cell 2021;184:1281-98.

11 Llibre A, López-Macías C, Marafioti T, et al. LLT1 and CD161 expression in human germinal centers promotes $\mathrm{B}$ cell activation and CXCR4 downregulation. J Immunol 2016;196:2085-94.

12 Germain C, Meier A, Jensen T, et al. Induction of lectin-like transcript 1 (LLT1) protein cell surface expression by pathogens and interferon- $\gamma$ contributes to modulate immune responses. $J$ Biol Chem 2011:286:37964-75.

13 Rosen DB, Cao W, Avery DT, et al. Functional consequences of interactions between human NKR-P1A and its ligand LLT1 expressed on activated dendritic cells and B cells. J Immunol 2008;180:6508-17.

14 Mathew SO, Chaudhary P, Powers SB, et al. Overexpression of LLT1 (OCIL, CLEC2D) on prostate cancer cells inhibits NK cell-mediated killing through LLT1-NKRP1A (CD161) interaction. Oncotarget 2016;7:68650-61.

15 Aldemir H, Prod'homme V, Dumaurier M-J, et al. Cutting edge: lectin-like transcript 1 is a ligand for the CD161 receptor. $J$ Immunol 2005;175:7791-5

16 Halkias J, Rackaityte E, Hillman SL, et al. CD161 contributes to prenatal immune suppression of IFN- $\gamma$-producing PLZF+ T cells. J Clin Invest 2019;129:3562-77.

17 Rosen DB, Bettadapura J, Alsharifi M, et al. Cutting edge: lectin-like transcript-1 is a ligand for the inhibitory human NKR-P1A receptor. $\mathrm{J}$ Immunol 2005;175:7796-9.

18 Punt S, Dronkers EAC, Welters MJP, et al. A beneficial tumor microenvironment in oropharyngeal squamous cell carcinoma is characterized by a high T cell and low IL-17(+) cell frequency. Cancer Immunol Immunother 2016:65:393-403.

19 Abdulrahman Z, de Miranda N, van Esch EMG. Pre-existing inflammatory immune microenvironment predicts the clinical response of vulvar high-grade squamous intraepithelial lesions to therapeutic HPV16 vaccination. J Immunother Cancer 2020;8.

20 Kenter GG, Welters MJP, Valentijn ARPM, et al. Vaccination against HPV-16 oncoproteins for vulvar intraepithelial neoplasia. $N$ Engl $J$ Med 2009;361:1838-47.

21 van Poelgeest MIE, Welters MJP, Vermeij R, et al. Vaccination against oncoproteins of HPV16 for noninvasive Vulvar/Vaginal lesions: lesion clearance is related to the strength of the T-cell response. Clin Cancer Res 2016:22:2342-50.

22 Oh SA, Seki A, Rutz S. Ribonucleoprotein transfection for CRISPR/ Cas9-mediated gene knockout in primary T cells. Curr Protoc Immunol 2019;124:e69.

23 ljsselsteijn ME, van der Breggen R, Farina Sarasqueta A, et al. A 40-marker panel for high dimensional characterization of cancer immune microenvironments by imaging mass cytometry. Front Immunol 2019;10:2534.

24 Guo X, Zhang Y, Zheng L, et al. Global characterization of T cells in non-small-cell lung cancer by single-cell sequencing. Nat Med 2018;24:978-85.
25 Zhang Y, Zheng L, Zhang L, et al. Deep single-cell RNA sequencing data of individual $T$ cells from treatment-naïve colorectal cancer patients. Sci Data 2019;6:131.

26 Zheng C, Zheng L, Yoo J-K, et al. Landscape of infiltrating T cells in liver cancer revealed by single-cell sequencing. Cell 2017;169:1342-56.

27 Di Tommaso P, Chatzou M, Floden EW, et al. Nextflow enables reproducible computational workflows. Nat Biotechnol 2017;35:316-9.

28 Exley M, Porcelli S, Furman M, et al. CD161 (NKR-P1A) costimulation of CD1d-dependent activation of human $T$ cells expressing invariant $\mathrm{V} \alpha 24 \mathrm{~J} \alpha \mathrm{Q}$ T cell receptor $\alpha$ chains. J Exp Med 1998:188:867-76.

29 Lin C-M, Lin L-W, Chen Y-W, et al. The expression and prognostic impact of proinflammatory cytokines and their associations with carcinogens in oropharyngeal squamous cell carcinoma. Cancer Immunol Immunother 2020;69:549-58.

30 Duhen T, Duhen R, Montler R, et al. Co-expression of CD39 and CD103 identifies tumor-reactive CD8 T cells in human solid tumors. Nat Commun 2018;9:2724.

31 Park BV, Freeman ZT, Ghasemzadeh A, et al. TGFbeta1-mediated SMAD3 enhances PD-1 expression on antigen-specific T cells in cancer. Cancer Discov 2016;6:1366-81.

32 Locci M, Wu JE, Arumemi F, et al. Activin a programs the differentiation of human TFH cells. Nat Immunol 2016;17:976-84.

33 Morianos I, Trochoutsou Al, Papadopoulou G. Correction for Morianos et al., activin-A limits Th17 pathogenicity and autoimmune neuroinflammation via CD39 and CD73 ectonucleotidases and Hif1- $\alpha$-dependent pathways. Proc Natl Acad Sci U S A 2020;117:12269-80.

34 Truong K-L, Schlickeiser S, Vogt K, et al. Killer-like receptors and GPR56 progressive expression defines cytokine production of human $\mathrm{CD}^{+}$memory T cells. Nat Commun 2019;10:2263.

35 Kortekaas KE, Santegoets SJ, Sturm G, et al. CD39 identifies the $\mathrm{CD}^{+}$tumor-specific T-cell population in human cancer. Cancer Immunol Res 2020;8:1311-21.

36 Koay H-F, Su S, Amann-Zalcenstein D, et al. A divergent transcriptional landscape underpins the development and functional branching of MAIT cells. Sci Immunol 2019;4:eaay6039.

37 Tsukumo S-ichi, Unno M, Muto A, et al. Bach2 maintains T cells in a naive state by suppressing effector memory-related genes. Proc Natl Acad Sci U S A 2013:110:10735-40.

38 Dejean AS, Joulia E, Walzer T. The role of Eomes in human CD4 T cell differentiation: a question of context. Eur J Immunol 2019;49:38-41.

39 Kakugawa K, Kojo S, Tanaka H, et al. Essential roles of SATB1 in specifying T lymphocyte subsets. Cell Rep 2017;19:1176-88.

40 Zhao X, Shan Q, Xue H-H. TCF1 in T cell immunity: a broadened frontier. Nat Rev Immunol 2021 doi:10.1038/s41577-021-00563-6

41 van de Wetering $\mathrm{M}$, Oosterwegel $\mathrm{M}$, van Norren $\mathrm{K}$, et al. Sox4, an Sry-like HMG box protein, is a transcriptional activator in lymphocytes. Embo J 1993;12:3847-54.

42 Duurland CL, Brown CC, O'Shaughnessy RFL, et al. CD161+ Tconv and CD $161^{+}$Treg Share a Transcriptional and Functional Phenotype despite Limited Overlap in TCR $\beta$ Repertoire. Front Immunol 2017:8:103.

43 Braud VM, Biton J, Becht E, et al. Expression of LLT1 and its receptor CD161 in lung cancer is associated with better clinical outcome. Oncoimmunology 2018;7:e1423184.

44 Gentles AJ, Newman AM, Liu CL, et al. The prognostic landscape of genes and infiltrating immune cells across human cancers. Nat Med 2015;21:938-45

45 Malhotra N, Qi Y, Spidale NA, et al. SOX4 controls invariant NKT cell differentiation by tuning TCR signaling. J Exp Med 2018;215:2887-900.

46 Sommers CL, Dejarnette JB, Huang K, et al. Function of CD3 epsilon-mediated signals in T cell development. J Exp Med 2000;192:913-9.

47 Bai A, Guo Y. Acid sphingomyelinase mediates human CD4 ${ }^{+}$T-cell signaling: potential roles in T-cell responses and diseases. Cell Death Dis 2017;8:e2963. 